\title{
Effect of the $\mathrm{CeO}_{2}$ synthesis method on the behaviour of $\mathrm{Pt} / \mathrm{CeO}_{2}$ catalysis for the water-gas shift reaction
}

\author{
L. Pastor-Pérez, E.V. Ramos-Fernández and A. Sepúlveda-Escribano*
}

Laboratorio de Materiales Avanzados, Departamento de Química Inorgánica - Instituto Universitario de Materiales de Alicante. Universidad de Alicante. Apartado 99, E-03080 Alicante, Spain.

\begin{abstract}
A comparative study of three different ceria synthesis procedures (template- and MWassisted hydrothermal synthesis and urea homogeneous precipitation) is reported in this paper. The obtained materials were employed as supports for Pt nanoparticles, and the $\mathrm{Pt} / \mathrm{CeO}_{2}$ catalysts were evaluated in the WGS reaction under model and realistic conditions. The influence of the support, e.g., its morphology and electronic properties, has been studied in detail by means of XRD, $\mathrm{H}_{2}$-TPR, XPS, UV-Vis spectroscopy and toluene hydrogenation (for metal dispersion assessment). The catalytic performance of the samples is directly correlated with the modification of the electronic properties, as a result of the preparation method used. The conventional homogeneous precipitation method with urea resulted to be the best option, leading to enhanced ceria reducibility and adequate Pt dispersion, which in turns resulted in a very efficient WGS catalyst.
\end{abstract}

Keywords: $\mathrm{Pt} / \mathrm{CeO}_{2}$; urea precipitation; microwave-assisted synthesis; polymer-assisted synthesis; WGS. 


\section{Introduction}

Cerium oxide (ceria, $\mathrm{CeO}_{2}$ ) is one of the most abundant rare-earth oxides, and it is very important in many catalytic processes where it is used as support for an active phase or by catalyst by itself $[1,2]$. Thus, it is an important component in the formulation of the three ways catalysts (TWCs) which are used to abate the toxic emissions of Otto engines [1,3], and also in Diesel engines, where it promotes the combustion of soot particles. Other emerging catalytic processes in which cerium oxides are been used are the oxidation of volatile compounds, reforming reactions, hydrogenation and hydrogenolysis reactions and water-gas shift, among others.

It is well recognized in the literature that the oxide's morphology is an important structural factor that can affect its chemical properties and, thus, its catalytic performance [1, 4-6]. In this sense, the surface composition and structure of $\mathrm{CeO}_{2}$ can greatly affect the nature and extent of the interaction between the active phase and its surface, when it is used as support for metal catalysts [7]. It has to be taken into account that the application of $\mathrm{CeO}_{2}$ as catalyst or catalyst support is mainly related to its surface reducibility, with the consequent formation of surface vacancies, which makes it a redox buffer [8]. This unique feature of ceria is termed as oxygen storage capacity (OSC), and it derives from the ability to be easily and reversibly reduced to several $\mathrm{CeO}_{2-\mathrm{x}}$ stoichiometries when it is exposed to $\mathrm{O}_{2}$ deficient atmospheres [9,10]. And it seems that this ability may depend on the oxide morphology, as different exposed surfaces may have different redox behaviours and interactions with the active phase. The most common method of ceria synthesis, precipitation from a cerium precursor solution by increasing the $\mathrm{pH}$, yields nanocrystals with irregular morphologies that expose several kinds of crystal planes. Such morphological complexity and inhomogeneity make it difficult to investigate and understand the effect of the $\mathrm{CeO}_{2}$ crystal`s morphology in the behaviour of ceria-supported catalysts. Consequently, a lot of work has been devoted to developing synthesis methods that allow preparing ceria particles with different morphologies and sizes [5].

Han et al. used a mild hydrothermal route to prepare ceria nanotubes, using ammonia solution as precipitation agent at large ageing times [11]. Liu et al. prepared ceria nanorods, also following a hydrothermal method, with different types and distributions of oxygen vacancies [12]. Some years later, $\mathrm{Wu}$ et al. investigated the catalytic behaviour of different ceria crystal surfaces in the $\mathrm{CO}$ oxidation reaction. To 
this end, they prepared ceria nanorods, nanocubes and octahedra, and observed different behaviours that were related to differences in the energetics of formation of surface oxygen vacancies, in such a way the reactivity for $\mathrm{CO}$ oxidation increased following the trend: rods > cubes > octahedra [13]. Désaunay et al. determined the surface dependency of hydrogen oxidation on ceria nanocrystals with different shapes exposing different surface planes: nanocubes exposing only (100) surfaces, octahedral exposing only (111) surfaces and nanorods exposing at least $50 \%$ of (110) surfaces [14]. The effect of the ceria particle shape on the interaction with a supported active phase has also been evidenced by several authors. Thus, the effect of the ceria particles shape in $\mathrm{Cu} / \mathrm{CeO}_{2}$ catalysts for $\mathrm{CO}$ oxidation has been recently studied by Lykaki et al. They observed the activity trend rods > polyhedral > cubes, which was the same for both ceria and $\mathrm{Cu} /$ ceria catalysts, and assigned this effect to the higher ability for the stabilization of $\mathrm{Cu}^{+}$species [15]. The effect of the ceria support has also been studied in platinum-based catalysts for different reactions. Thus, Gao et al. observed a strong morphology effect in platinum supported on ceria rods, cubes and octahedral in the preferential oxidation of $\mathrm{CO}$ in a $\mathrm{H}_{2}$-rich stream (CO-PROX), which they correlated with the exposed crystal planes [16]. Tong et al. also observed a very important effect of the ceria crystal planes exposed in Pt/ceria catalysts for the hydrogenolysis of furfuryl alcohol to 1,2-pentanediol [17]. In this case, they concluded that the reaction selectivity was determined by the chemical state of platinum, which was in turn controlled by the extent of the metal-support interaction with the ceria surface via the oxygen vacancies. The best catalytic performance was obtained in the Pt/ceria nanocube system exposing the (100) ceria surface.

One of the potential applications of ceria as support is in the preparation of catalysts for the water-gas shift reaction that it is used for balancing the $\mathrm{H}_{2} / \mathrm{CO}$ ratio in reforming streams $\left(\mathrm{CO}+\mathrm{H}_{2} \mathrm{O} \rightarrow \mathrm{CO}_{2}+\mathrm{H}_{2}\right)$ [18-20]. It provides a source of hydrogen at the expenses of carbon monoxide, which is also important for the production of high purity hydrogen. Specifically, the use of ceria as support contributes to the WGS reaction by facilitating the redox process, as it provides activated oxygen to oxidize the $\mathrm{CO}$ adsorbed on the metal. However, the effect of the support characteristics and how they affect the catalytic behaviour in this reaction is usually relegated to a second plane or not even mentioned. 
As an example, one of the critical factors, together with the redox properties of the ceria support, is the dispersion of Pt on the support, which also depends on the ceria surface chemistry. It has been shown that the interaction between Pt and ceria-based oxides can inhibit Pt growth and sintering. Previous studies by Efstathiou et al, reported that Pt particle size has an effect on the intrinsic WGS kinetic rate [21]. Furthermore, the Pt-Ce interaction can result in a synergic effect, improving the catalytic activity [22].

Si and Flytzani-Stephanopoulos prepared gold nanoparticles supported on ceria nanorods, nanocubes and nanopolyhedra, and they observed a strong effect of ceria shape on the catalytic activity for the water-gas shift (WGS) reaction, being gold supported on the (110) surface of ceria nanorods the most active catalyst [23]. However, there are very few studies on the effect of ceria morphology in Pt-based catalysts for WGS. One of the latest is the work by Torrente-Murciano and García-García, who studied the catalytic behaviour in WGS of Pt/ceria catalysts using supports with different morphologies (rods, cubes and irregular nanoparticles). They showed that the best results in terms of hydrogen yield and low methane selectivity were obtained when ceria nanorods were used and claimed that it was related to the preferential exposure of the (110) crystal plane [24]. Despite that there is not much information in the literature, there are some discrepancies on this possible support morphology effect. Kondaries et al. concluded that activity of $\mathrm{Pt} / \mathrm{CeO}_{2}$ does not depend on the structural and morphological characteristics of the support, at least in the range of surface areas (3.3$57 \mathrm{~m}^{2} / \mathrm{g}$ ) and primary crystallite sizes (10-32 $\mathrm{nm}$ ) they tested [25].

Based on the above, in this work we have tried to deepen in the different properties that can be achieved through the preparation of $\mathrm{CeO}_{2}$ supports employing different synthesis methods, and carried out a thorough comparison in their behaviour when they are used as catalysts in the water-gas shift reaction. Irregular $\mathrm{CeO}_{2}$ nanoparticles were prepared by a simple and facile conventional precipitation method. In order to investigate the effect of the structure and morphology of $\mathrm{CeO}_{2}$ in the catalytic performance, two more methods to obtain controlled surface morphology/structure of $\mathrm{CeO}_{2}$ were chosen: a fast template-free method assisted by microwaves and a template (polymer)-assisted method under hydrothermal conditions. In addition, the effect of the $\mathrm{Pt}$ dispersion and $\mathrm{Pt}-\mathrm{CeO}_{2}$ interactions on different ceria supports was investigated. Different catalytic performances of these $\mathrm{Pt} / \mathrm{CeO}_{2}$ samples in the water-gas shift reaction (WGS) were obtained. 


\section{Experimental}

\section{Catalysts preparation}

Three $\mathrm{CeO}_{2}$ supports were prepared employing different synthesis methods. For $\mathrm{CeO}_{2}$-Urea, homogeneous precipitation with urea was used. Thus, an aqueous solution of $\mathrm{Ce}\left(\mathrm{NO}_{3}\right)_{3} \cdot 6 \mathrm{H}_{2} \mathrm{O}(99.99 \%$, Sigma-Aldrich) containing an excess of urea was heated at $80{ }^{\circ} \mathrm{C}$ and kept at this temperature, with smooth stirring, for $12 \mathrm{~h}$. The solid formed was filtered and calcined at $350{ }^{\circ} \mathrm{C}$ for $4 \mathrm{~h}$.

$\mathrm{CeO}_{2}-\mathrm{MW}$ was prepared by microwave-assisted hydrothermal synthesis. A certain amount of $\mathrm{Ce}\left(\mathrm{NO}_{3}\right)_{3} \cdot 6 \mathrm{H}_{2} \mathrm{O}(99.99 \%$, Sigma-Aldrich) and the required amount of urea were dissolved in water. The reaction solution was poured into a Teflon-lined autoclave which was sealed and placed into a programmable microwave oven (Milestone, Ethos One). The oven was heated to $170{ }^{\circ} \mathrm{C}$ in $2 \mathrm{~min}$ and then kept at this temperature for 30 minutes by microwave irradiation. After cooling to room temperature, the sample was filtered and dried. Finally, the solid was calcined during 4 $\mathrm{h}$ at $350^{\circ} \mathrm{C}$.

Finally, a polymer-assisted hydrothermal synthesis was used for the preparation of $\mathrm{CeO}_{2}$-Template. In this route, the corresponding amount of $\mathrm{Ce}\left(\mathrm{NO}_{3}\right)_{3} \cdot 6 \mathrm{H}_{2} \mathrm{O}(99.99 \%$, Sigma-Aldrich), $2.9 \mathrm{mmol}$ of $\mathrm{CeO}_{2}$, was dissolved in water, and the resulting solution was added to an aqueous solution containing $0.15 \mathrm{mmol}$ P123 (poly(ethylene glycol)poly(propylene glycol)-poly(ethylene glycol) (P123, Sigma-Aldrich) with a molecular weight of $5800 \mathrm{~g}$. The solution was homogenized by stirring for $1 \mathrm{~h}$ and then, $0.8 \mathrm{mmol}$ of urea was added and the solution was stirred again for $3 \mathrm{~h}$. The final solution was then transferred to a stainless steel autoclave with an inside Teflon liner and subjected to heating at $120^{\circ} \mathrm{C}$ for $24 \mathrm{~h}$. The autoclave was then allowed to cool to room temperature, and after ageing the resultant product for $24 \mathrm{~h}$, the solid was filtered and repeatedly washed with distilled water. After drying in an oven at $100{ }^{\circ} \mathrm{C}$, the solid was treated at $350{ }^{\circ} \mathrm{C}$ for $4 \mathrm{~h}$ under flowing $\mathrm{He}(50 \mathrm{~mL} / \mathrm{min})$.

$\mathrm{CeO}_{2}$-supported $\mathrm{Pt}$ catalysts were prepared by impregnation by an excess of solvent. The corresponding amount of $\mathrm{H}_{2} \mathrm{PtCl}_{6} \cdot 6 \mathrm{H}_{2} \mathrm{O}(99.99 \%$, Alfa Aesar) was dissolved in acetone to obtain catalysts with $1 \mathrm{wt} . \%$ Pt. Calcined $\mathrm{CeO}_{2}$ was added to the solution, in a proportion of $10 \mathrm{~mL} / \mathrm{g}$ of support, with stirring. After $12 \mathrm{~h}$, the excess of 
solvent was slowly removed under vacuum and then dried in the oven until complete removal of the solvent. Finally, the solids were calcined $4 \mathrm{~h}$ at $350{ }^{\circ} \mathrm{C}$. The three prepared catalysts are labelled as $\mathrm{Pt} / \mathrm{CeO}_{2}$-Urea, Pt- $\mathrm{CeO}_{2}-\mathrm{Microwave}$ and $\mathrm{Pt}-\mathrm{CeO}_{2}$ Template.

\section{Catalysts characterization}

The textural properties of the supports were characterized by nitrogen adsorption measurements at $-196^{\circ} \mathrm{C}$. Gas adsorption experiments were performed in a home-made fully automated volumetric equipment. Prior to the adsorption experiments, samples were out-gassed under vacuum $\left(10^{-4} \mathrm{~Pa}\right)$ at $250{ }^{\circ} \mathrm{C}$ for $4 \mathrm{~h}$. The "apparent" surface area was estimated after application of the BET equation.

The actual metal loading of the different catalysts was determined by ICP-OES in a Perkin-Elmer device (Optimal 3000). To this end, the metal was extracted from the catalysts by digestion in aqua regia for $30 \mathrm{~min}$ in a microwave oven (Milestone, Ethos One) at $180{ }^{\circ} \mathrm{C}$.

X-Ray powder diffraction patterns were recorded on a Bruker D8-Advance with a Göebel mirror and a Kristalloflex K 760-80 F X-Ray generation system, fitted with a $\mathrm{Cu}$ cathode and a Ni filter. Spectra were registered between 20 and $80^{\circ}(2 \theta)$ with a step of $0.05^{\circ}$ and a time per step of $3 \mathrm{~s}$.

Scanning electron microscopy (SEM) and the semi-quantitative elemental analysis was obtained by energy dispersive X-ray spectroscopy (EDS). SEM/EDS analyses were performed on a JEOL JSM 35C/Noran Voyager system.

TEM observations were carried out on a JEOL electron microscope (model JEM-2010) working at $200 \mathrm{kV}$. It was equipped with an INCA Energy TEM 100 analytical system and a SIS MegaView II camera. Samples for analysis were suspended in ethanol and placed on copper grids with a holey-carbon film support.

Electronic modification (Band gap) of the solids was analysed with an integrating sphere ISV-722 UV-Visible containing the Jasco V-650 M, a double-beam spectrophotometer with a photomultiplier tube detector.

Temperature-programmed reduction (TPR) with $\mathrm{H}_{2}$ measurements were carried out on calcined catalysts in a U-shaped quartz cell using a $5 \% \mathrm{H}_{2} / \mathrm{He}$ gas flow of 50 
$\mathrm{mL} / \mathrm{min}$, with a heating rate of $10^{\circ} \mathrm{C} / \mathrm{min}$. Samples were treated with flowing He at 150 ${ }^{\circ} \mathrm{C}$ for $1 \mathrm{~h}$ before the TPR run. Hydrogen consumption was followed by on-line mass spectrometry.

X-Ray photoelectron spectroscopy was performed with a K-ALPHA spectrometer (Thermo Scientific). All spectra were collected using Al-K $\alpha$ radiation $(1486.6 \mathrm{eV})$, monochromatized by a twin crystal monochromator, yielding a focused $\mathrm{X}$ ray spot with a diameter of 400_m, at $3 \mathrm{~mA} \times 12 \mathrm{kV}$. The alpha hemispherical analyser was operated at the constant energy mode with survey scan pass energies of $200 \mathrm{eV}$ to measure the whole energy band and $50 \mathrm{eV}$ in a narrow scan to selectively measure the particular elements. Charge compensation was achieved with the system flood gun that provides low energy electrons and low energy argon ions from a single source. The powder samples were pressed and mounted on the sample holder and placed in the vacuum chamber. Before recording the spectrum, the samples were maintained in the analysis chamber until a residual pressure of ca. $5 \times 10^{-7} \mathrm{~N} \cdot \mathrm{m}^{-2}$ was reached. The quantitative analysis was estimated by calculating the integral of each peak, after subtracting the S-shaped background, and by fitting the experimental curve to a combination of Lorentzian (30\%) and Gaussian (70\%) lines.

\section{Catalytic behaviour}

Two different catalytic reactions have been used with the $\mathrm{Pt} / \mathrm{CeO}_{2}$ catalysts to investigate the effect of the structure and morphology of the different $\mathrm{CeO}_{2}$ supports prepared, toluene hydrogenation and water-gas shift (WGS).

The catalytic behaviour of the catalysts in the toluene hydrogenation reaction has been used to estimate differences in Pt dispersion in the different catalysts. This reaction has a structure-insensitive character, which makes the catalytic activity to depend only on the number of metallic sites available at the surface. The catalytic activity of the prepared catalysts was compared to the activity of a commercial one ( $\mathrm{Pt} / \mathrm{Al}_{2} \mathrm{O}_{3}$, Sigma Aldrich) whose metallic dispersion has been accurately determined by TEM analysis, using the following equation:

$$
D=\frac{6 \cdot V_{m}}{a_{m} \cdot d V_{A}}
$$


where $\mathrm{dV}_{\mathrm{A}}$ is the average diameter of Pt particles (measured by TEM), $\mathrm{a}_{\mathrm{m}}$ is the area per Pt atom on the surface, $\mathrm{a}_{\mathrm{m}}=\pi \mathrm{r}_{\mathrm{Pt}}{ }^{2} ; \mathrm{V}_{\mathrm{m}}$ is the Pt atomic volume, $\mathrm{V}_{\mathrm{m}}=(4 \pi / 3) \mathrm{r}_{\mathrm{Pt}}{ }^{3}$, and $\mathrm{r}_{\mathrm{Pt}}=$ $1.38 \cdot 10^{-10} \mathrm{~cm}$.

Toluene hydrogenation tests were performed in a U-shape quartz reactor at atmospheric pressure, and the products were monitored by on-line gas chromatograph $($ Agilent $6890 \mathrm{~N})$ with a flame ionization detector and HP-Plot/Q $(30 \mathrm{~m} \times 0.53 \mathrm{~mm})$ column. Prior to reaction, the samples $(20 \mathrm{mg})$ were reduced in situ at $350{ }^{\circ} \mathrm{C}$ for $2 \mathrm{~h}$ under flowing hydrogen $(50 \mathrm{~mL} / \mathrm{min})$. The reaction was evaluated at $60{ }^{\circ} \mathrm{C}$, with a total flow of $50 \mathrm{~mL} / \mathrm{min}$ containing hydrogen and toluene in $\mathrm{H}_{2} / \mathrm{C}_{7} \mathrm{H}_{8}$ ratio of 36 , obtained by passing the hydrogen flow through a thermos-stabilized saturator containing toluene at $20^{\circ} \mathrm{C}$.

The catalytic behaviour of the prepared samples in the low-temperature watergas shift reaction was evaluated in a fixed bed flow reactor under atmospheric pressure in the range of temperatures from 160 to $360{ }^{\circ} \mathrm{C}$. Two different feed gas mixtures were used, both of them with a total flow of $100 \mathrm{~mL} / \mathrm{min}$. The idealized feed gas mixture contained $5 \% \mathrm{CO}$ and $30 \mathrm{~mol} \% \mathrm{H}_{2} \mathrm{O}$ in $\mathrm{He}$; on the other hand, trying to simulate a closer to actual outgas mixture from a reformer, experiments with a feed gas composition of $7 \mathrm{~mol} \% \mathrm{CO}, 30 \mathrm{~mol} \% \mathrm{H}_{2} \mathrm{O}, 50 \mathrm{~mol} \% \mathrm{H}_{2}$, and $9 \mathrm{~mol} \% \mathrm{CO}_{2}$ in helium were carried out. Activity tests were performed using $0.150 \mathrm{~g}$ of catalyst diluted with $\mathrm{SiC}$, to avoid thermal effects. The corresponding WHSV was $40000 \mathrm{~mL} / \mathrm{g} \cdot \mathrm{h}$. Prior to reaction, the catalysts were reduced under flowing $\mathrm{H}_{2}(50 \mathrm{~mL} / \mathrm{min})$ for $2 \mathrm{~h}$ at $350{ }^{\circ} \mathrm{C}$. The composition of the gas stream exiting the reactor was determined by mass spectrometry (Pfeiffer, OmniStar GSD 301), and the catalytic activity will be expressed by degree of $\mathrm{CO}$ conversion as a function of the reaction temperature. The stabilization time for each temperature was $1 \mathrm{~h}$ and the $\mathrm{CO}$ conversion percentage was calculated by this equation:

$$
\mathrm{CO} \text { conversion }(\%)=100-\left(x \mathrm{CO} / x \mathrm{CO}_{\text {initial }}\right) \cdot 100
$$

where $x \mathrm{CO}$ is the concentration of $\mathrm{CO}$ in the outlet of the reactor and $x \mathrm{CO}_{\text {initial }}$ is the $\mathrm{CO}$ concentration in the initial gas mixture. The carbon balance was checked taking into account all the carbon-containing products.

\section{Results and discussion}




\section{Catalysis characterization}

The powder X-ray diffraction (XDR) patterns of the $\mathrm{CeO}_{2}$ supports after the calcination treatment are shown in Fig. 1. The characteristic $\mathrm{CeO}_{2}$ peaks (JCPDS 340394, space group Fm3m) at 28.6, 33.4, 47.8, 56.7, 59.1, 69.4, 76.7, and 79.1 ${ }^{\circ}$, corresponding to reflections in the (111), (200), (220), (331), (222), (400), (331), (420) and (422) crystalline planes of the cubic fluorite-type phase respectively, can be clearly observed. By application of the Scherrer equation to the (111) diffraction peak, the mean crystal sizes of $\mathrm{CeO}_{2}$ in the different supports have been determined, and they are presented in the table inserted in Fig. 1. The $\mathrm{CeO}_{2}$-Template support presents the lowest crystallite size $(9.3 \mathrm{~nm})$. It is known that the selective surface adsorption properties of P123 prevent agglomerations, frenzied crystal growth, and structural disorganization of nascent crystallites [26]. Regarding microwave and urea synthesis, they lead to a similar ceria particle size of ca. $12 \mathrm{~nm}$.

XRD profiles of $\mathrm{Pt} / \mathrm{CeO}_{2}$ catalysts (not shown) only exhibit the peaks that belong to the $\mathrm{CeO}_{2}$ phase, whereas no diffraction peaks belonging to Pt species could be detected. This indicates that the dispersion of the metallic particles over the $\mathrm{CeO}_{2}$ supports occurred presumably without the formation of large crystalline particles.

Table 1 shows the specific surface area $\left(\mathrm{N}_{2},-196{ }^{\circ} \mathrm{C}\right.$, BET), the micropore volume $\left(\mathrm{V}_{\text {micro }}, \mathrm{N}_{2},-196{ }^{\circ} \mathrm{C}, \mathrm{D}-\mathrm{R}\right)$ and the volume of mesopores $\left(\mathrm{V}_{\text {meso }}\right)$ for the three supports, as well as the actual Pt loading (ICP analysis) of the three catalysts. The $\mathrm{N}_{2}$ adsorption isotherms at $-196{ }^{\circ} \mathrm{C}$ for all supports (Fig. 2) correspond to a combination of Type I and Type IV isotherms (according to the IUPAC classification) [27], showing the presence of some microporosity (steep increase of the amount adsorbed at very low relative pressure) and a small contribution of mesopores (hysteresis loop) mostly formed by particle agglomeration, as inter-particle porosity. Regarding $\mathrm{CeO}_{2}-\mathrm{MW}$, the higher contribution of mesopores in this sample is very likely due to the void space among the stacked hollow spheres [28]. In contrast, the lack of any defined morphology favouring a more compact agglomeration of particles could be the reasons behind the lower mesoporosity in the $\mathrm{CeO}_{2}$-Urea sample [29].

Finally, the actual $\mathrm{Pt}$ content of the catalysts was determined by ICP measurements, and the results are reported in Table 1. The obtained values match the nominal ones, confirming the successful Pt deposition. 
The surface morphological characteristics of the calcined $\mathrm{CeO}_{2}$ samples were investigated by SEM and TEM analysis (Fig. 3). The $\mathrm{CeO}_{2}$-Urea sample shows a typical SEM image of polyhedrical $\mathrm{CeO}_{2}$ particles. During the urea homogeneous precipitation process, the kinetically slow nucleation of $\mathrm{Ce}^{3+}$ with the increasing of the $\mathrm{pH}$ due to the formation of $\mathrm{OH}^{-}$and $\mathrm{CO}_{3}{ }^{2-}$ ions (from the hydrolysis and decomposition of urea) produces $\mathrm{Ce}_{2} \mathrm{O}-\left(\mathrm{CO}_{3}\right)_{2} \cdot \mathrm{H}_{2} \mathrm{O}$ and $\mathrm{Ce}(\mathrm{OH})_{3}$ seeds, followed by nanocrystals. The coalesced/ripened nanocrystals undergo random growth under thermal conditions (calcination), leading to the formation of heterogeneous polyhedra-like microcrystals [28]. However, the $\mathrm{CeO}_{2}-\mathrm{MW}$ and $\mathrm{CeO}_{2}$-Template samples show a well-defined and structured morphology in contrast to the $\mathrm{CeO}_{2}$-Urea. The SEM image of $\mathrm{CeO}_{2}-\mathrm{MW}$ support (Fig. 3.A1) shows that nearly monodispersed (in size) nanospheres are obtained. A closer examination by TEM indicates that the entire structure of the sphere consists of many small nanoparticles (Fig. 3.A2). An Ostwald ripening coupled self-templated, self-assembly process for the formation of the $\mathrm{CeO}_{2}$ hollow nanospheres is proposed [28]. For the $\mathrm{CeO}_{2}$-Template support, the grain/ripened nanocrystals under selective crystal-facet adhesion of polymer molecules undergo kinetic shape control, producing rod-shape structures [29]. It is worth to mention that these three differently shaped ceria nanoparticles maintain their original shapes after platinum deposition (not shown).

The electronic properties of the studied supports and catalysts were obtained by UV-Vis spectroscopy analysis. The UV-Vis spectra of all samples are shown in Fig. 4. All the samples presented the characteristic absorption region associated with $\mathrm{CeO}_{2}$ and assigned to a charge transfer $\mathrm{O}_{2 p} \rightarrow \mathrm{Ce}_{4 f}$ transition. Two bands can be seen for all $\mathrm{CeO}_{2}$ samples with different morphologies at about $277 \mathrm{~nm}$, corresponding to an $\mathrm{O}^{2-} \rightarrow \mathrm{Ce}^{4+}$ charge transfer, and at $347 \mathrm{~nm}$, attributed to inter-band transitions [30]. Furthermore, the absorption band at $255 \mathrm{~nm}$, corresponding to an $\mathrm{O}^{2-} \rightarrow \mathrm{Ce}^{3+}$ charge transfer, could be intuited.

For further understanding, indirect band gaps of the samples were estimated by the Kubelka-Munk function, and are listed in Table 2. The band gaps obtained for the three ceria supports are smaller than that found in ceria single crystals $(3.02 \mathrm{eV})[31,32]$. The experimental band structure of $\mathrm{CeO}_{2}$ is described considering the valence and conduction bands from $\mathrm{O}_{2 p}$ and $\mathrm{Ce}_{5 d}$ states, respectively, separated ca. $6 \mathrm{eV}$. Between these two bands, the $\mathrm{Ce}_{4 f}$ band appears. For defect-free crystals, the later is empty and lies around ca. $3 \mathrm{eV}$ above the valence band, but if it becomes partially occupied, their 
energy separation with the valence band decreases. The $\mathrm{Ce}_{4 f}$ band becomes partially occupied when $\mathrm{Ce}^{3+}$ is present. So, the reduction of the band gap is associated with the presence of $\mathrm{Ce}^{3+}$ that enhances the photon absorption in the visible region [7,33]. This description results in a fairly localized picture of the $4 \mathrm{f}$ electrons that remain on the cerium ions resulting in $\mathrm{Ce}^{3+}$ ions [34]. The reason for this red-shift band gap in our $\mathrm{CeO}_{2}$ samples must be associated with the higher ratio of $\mathrm{Ce}^{3+}$ to $\mathrm{Ce}^{4+}$ species. As the $\mathrm{Ce}^{3+}$ ions concentration increases, a decrease in the band gap is observed [35,36]. This is associated with the population of the defect state, oxygen vacancies and the presence of partially reduced ceria on the catalysts surface, as reported elsewhere [24]. Besides, the difference in the concentration of $\mathrm{Ce}^{3+}$ ions can be attributed to the different morphologies [38]. These surface defects such as oxygen vacancies can prevent hole-electron recombination, working as electron traps, and can also act as strong binding and dissociation sites for adsorbates [39]. Considering the three $\mathrm{CeO}_{2}$ samples, the lowest band gap was obtained for the $\mathrm{CeO}_{2}$-Urea support, this evidencing the higher population of $\mathrm{Ce}^{3+}$ ions and oxygen vacancies in this sample [40]. Some studies reported that the difference in the $\mathrm{Ce}^{3+}$ contents is originated from the exposed surface planes of the $\mathrm{CeO}_{2}$ supports; concretely, the desorption of oxygen occurs more easily for the (100) and (110) surfaces than for the most stable (111) planes [41]. Therefore, these results indicated that the different morphologies of the $\mathrm{CeO}_{2}$ supports can result in different coordination environments of the supported Pt particles.

Additionally, the UV-Vis spectra and the band gap of the $\mathrm{Pt} / \mathrm{CeO}_{2}$ catalysts are also shown in Fig. 4 and Table 2, respectively. It can be observed that Pt remarkably reduces the material's band gap, this suggesting the insertion of metal levels between the valence and conduction bands of ceria and pointing to a strong metal-support interaction [35]. In addition, the enhanced ceria reducibility due to the intimate Pt-ceria contact may induce band gap contraction, as previously observed [37]. These data suggest that an electron transfer process may take place at the interface between ceria and metal "in facilitating the redox properties of the ceria" [42]. It is also remarkable that the catalyst prepared by using the urea-assisted method shows the lowest band gap [43].

$\mathrm{H}_{2}$-TPR measurements were employed in order to assess the redox properties of the supports and catalysts; the obtained TPR profiles are presented in Fig. 5. TPR 
profiles of supports are rather similar, and only two peaks are shown at 450 and $800{ }^{\circ} \mathrm{C}$, which are associated with the reduction of surface and bulk ceria, respectively $[33,35]$.

Fig. 5B shows the TPR profiles obtained with the catalysts, which are similar to those reported in the literature for Pt-ceria systems [44-47]. The first intense peak centred at low temperatures is assigned to the surface reduction of ceria in close contact with the metal, as well as the platinum reduction (breakdown of $\mathrm{Pt}-\mathrm{O}-\mathrm{CeO}_{2}$ species created upon calcination). In addition, the presence of Pt shifted the ceria surface reduction process towards lower temperatures, evidencing the metal phase-support intimacy, which promotes ceria reducibility. This effect agrees with previous studies on $\mathrm{Pt} / \mathrm{CeO}_{2}$ catalysts [48, 49]. The second peak (not shown, and located at high temperatures between 600 and $900{ }^{\circ} \mathrm{C}$ ) is ascribed to the $\mathrm{CeO}_{2}$ bulk reduction. However, further analysis reveals that our samples present different TPR profiles. For the $\mathrm{Pt} / \mathrm{CeO}_{2}$-Urea catalysts, the first peak appears at lower temperatures than the peak for their counterparts, this pointing to higher oxygen mobility in this sample. Presumably, the enhanced oxygen mobility of this sample is related to the higher population of oxygen vacancies in the sample (as shown by UV analysis) and/or to a better platinum dispersion inducing a maximized $\mathrm{Pt}-\mathrm{CeO}_{2}$ interaction. On the other hand, the peak at a lower temperature for the $\mathrm{Pt} / \mathrm{CeO}_{2}$-Template catalyst has a smaller area, and the presence of two overlapped peaks is noticed. The poorer hydrogen consumption indicates a lower ceria reduction degree, what can be assigned to smaller $\mathrm{Pt}-\mathrm{CeO}_{2}$ interface which could be related to larger Pt particles. The presence of two reduction peaks also suggests different $\mathrm{Pt}-\mathrm{CeO}_{2}$ interactions. The $\mathrm{Pt} / \mathrm{CeO}_{2}-\mathrm{MW}$ sample presents only one reduction process at approximately the same temperatures than that of the $\mathrm{Pt} / \mathrm{CeO}_{2}-\mathrm{Template}$ catalyst.

In order to assess the dispersion and the chemical state of $\mathrm{Pt}$ on the ceria supports, the reduced samples have been analyzed by XPS. The catalysts were reduced ex-situ at $350{ }^{\circ} \mathrm{C}$ under flowing $\mathrm{H}_{2}$ and conserved in octane until the analysis. The binding energies (B.E.) of the $\mathrm{Pt}^{0} 4 f_{7 / 2}$ core level, the surface $\mathrm{Pt} / \mathrm{Ce}$ atomic ratio and the surface $\mathrm{Ce}^{3+}$ content $(\%)$ are summarized in Table 3. Fig. 6 shows the XPS spectra of the Pt $4 f$ core level. The spectrum of the $\mathrm{Pt} / \mathrm{CeO}_{2}$-Urea sample has two well-defined peaks that are ascribed to the spin-orbit component of the $\mathrm{Pt} 4 f$ level. The peaks are centred at $72.7 \mathrm{eV}\left(\mathrm{Pt} 4 f_{7 / 2}\right)$ and at $75.9 \mathrm{eV}\left(\mathrm{Pt} 4 f_{5 / 2}\right)$. It means that there is only one type of Pt species. The other two samples show different spectra, which in both cases can be 
deconvoluted in four peaks indicating that there are two platinum species in these samples. In order to simplify the discussion, for now on we will focus on the $4 f_{7 / 2}$ level [50]. Coming back to the urea-based sample, the $4 f_{7 / 2}$ peak is located at $72.7 \mathrm{eV}$ and can be ascribed to oxidic platinum species. If we look up the TPR profile of this sample (Fig. 5), the platinum particles should be reduced during the hydrogen pretreatment. We think that the platinum species generated in this catalyst are strongly interacting with the support that actually has more oxygen vacancies. In fact, the TPR results indicate that the oxygen vacancies are generated at a lower temperature in this catalyst, which is also demonstrated by the UV-Vis analysis. The presence of these oxygen vacancies, together with the high platinum-support interaction, induces an electronic transfer where platinum particles tend to maintain some positive charge and to increase ceria reducibility. It can be seen in Table 3 that the binding energies of the $\mathrm{Pt} 4 f$ core level spectra shift to lower values in the following order: $\mathrm{Pt} / \mathrm{CeO}_{2}-\mathrm{Urea}>\mathrm{Pt} / \mathrm{CeO}_{2}-\mathrm{MW}$ > $\mathrm{Pt} / \mathrm{CeO}_{2}$-Template. This is also the trend for the decrease of the $\mathrm{Ce}^{3+}$ content in the samples (Table 3). As will be discussed below, also the catalytic behaviour follows this sequence.

The assessment of the metallic dispersion by gas chemisorption in supported metal catalysts containing ceria is not easy, as ceria is also able to chemisorb $\mathrm{H}_{2}$ and $\mathrm{CO}$ at room temperature, this producing an overestimation of the metal surface exposed. Nevertheless, an estimation of the amount of Pt surface atoms in these samples can be achieved by determining their catalytic activity in a structure-insensitive reaction. Specifically, toluene hydrogenation in the vapour phase has been used as a test reaction to estimate the amount of Pt atoms exposed in the ceria-supported catalysts $[8,51]$. In this sense, catalytic activity for toluene hydrogenation obtained for all samples after reduction at $350{ }^{\circ} \mathrm{C}$ was compared with the activity of a well-characterized $\mathrm{Pt} / \mathrm{Al}_{2} \mathrm{O}_{3}$ commercial catalyst [52]. In this way, Table 3 shows an estimation of the Pt dispersion in the three $\mathrm{Pt} / \mathrm{CeO}_{2}$ samples. As it can be seen, the values decrease in this order: $\mathrm{Pt} / \mathrm{CeO}_{2}-$ Urea > $\mathrm{Pt} / \mathrm{CeO}_{2}-\mathrm{MW}>\mathrm{Pt} / \mathrm{CeO}_{2}-$ Template, which is the same trend than that showed by the surface Pt/Ce ratios obtained by XPS. These data confirm the higher amount of surface $\mathrm{Pt}$ atoms available in the $\mathrm{Pt} / \mathrm{CeO}_{2}$-Urea catalyst. Summarizing the characterization results, we can see that the different preparation methods lead to different electronic properties of the support as well as different Pt dispersion. It for sure will have a large influence in the catalytic performance. 


\section{Catalytic behaviour}

Fig. 7 shows the WGS catalytic activity of the studied samples under model conditions $\left(\mathrm{CO}+\mathrm{H}_{2} \mathrm{O}\right)$. Pt/ $/ \mathrm{CeO}_{2}-\mathrm{Urea}$ and $\mathrm{Pt} / \mathrm{CeO}_{2}-\mathrm{MW}$ catalysts exhibited similar behaviour, reaching full equilibrium conversions above $300{ }^{\circ} \mathrm{C}$. In contrast, the $\mathrm{Pt} / \mathrm{CeO}_{2}-\mathrm{Template}$ catalyst was out of the trend, resulting hardly active in this reaction.

In order to differentiate the catalytic properties of the $\mathrm{Pt} / \mathrm{CeO}_{2}$-Urea and $\mathrm{Pt} / \mathrm{CeO}_{2}-\mathrm{MW}$ samples, a most demanding WGS inlet was considered. Actually, with the aim to use the WGS reaction as a CO removal step for fuel cells applications, the presence of $\mathrm{CO}_{2}$ and $\mathrm{H}_{2}$ must be considered [53]. Fig. 8 represents the catalytic activity of the studied solids under more realistic feed composition. As expected, the conversion curves shift to higher temperatures when $\mathrm{CO}_{2}$ and $\mathrm{H}_{2}$ are included due to reaction thermodynamics constraints. With these new conditions, the catalytic activity follows this trend: $\mathrm{Pt} / \mathrm{CeO}_{2}-\mathrm{Urea}>\mathrm{Pt} / \mathrm{CeO}_{2}-\mathrm{MW}>\mathrm{Pt} / \mathrm{CeO}_{2}-$ Template. As observed in the model mixture, the $\mathrm{Pt} / \mathrm{CeO}_{2}$-Template sample is the least active within the series. According to the characterization data, this catalyst exhibits the poorest reducibility together with the lowest Pt dispersion. Both properties affect the WGS performance and could explain its insufficient activity. While in the model WGS mixture both $\mathrm{Pt} / \mathrm{CeO}_{2}-\mathrm{Urea}$ and $\mathrm{Pt} / \mathrm{CeO}_{2^{-}}$ MW behaved similarly, the $\mathrm{Pt} / \mathrm{CeO}_{2}$-Urea sample manifested the best catalytic activity under the realistic stream. Several reasons may account for the promoted activity of this sample as deduced from the characterization data.

For the water-gas shift reaction, water dissociation may take place either on the support and the metal particle in the case of $\mathrm{Pt} / \mathrm{CeO}_{2}$ catalysts. Apparently, the key step in the preparation of highly efficient catalysts for the WGS reaction is the presence also of an adequate support with high oxygen mobility able to assists the rate-limiting step water activation $[19,54]$. Our TPR and XPS results reveal that the $\mathrm{Pt} / \mathrm{CeO}_{2}-\mathrm{Urea}$ sample presents the highest reducibility. The enhanced redox properties are associated with electronics perturbations resulting from the strong metal-support contact. As previously reported, this kind of metal particles-support interactions could explain the excellent catalytic activity [33]. In addition to the reducibility, the lowest band gap was observed for the $\mathrm{CeO}_{2}$-Urea support (UV-Vis experiments) indicated a larger concentration of $\mathrm{Ce}^{3+}$ ions and oxygen vacancies in the sample. Such structural defects play an important 
role in the catalytic activity, acting as adsorption points for water activation and assisting the noble metal to complete the catalytic cycle.

In other words, in the WGS redox pathway, it is well known that the formation of carboxyl species takes place in the oxygen vacancies of the support. Consequently, the differences in the activity between the three $\mathrm{Pt} / \mathrm{CeO}_{2}$ catalysts can be explained on the basis of different reaction pathways [55]. In the redox mechanism, $\mathrm{CO}$ adsorbs on $\mathrm{Pt}$ surface sites and it is oxidized by oxygen species from $\mathrm{CeO}_{2}$ which, in turn, is reoxidized by water that adsorbs on the oxide surface generating hydroxyl groups bound to the oxygen vacancies. The main difference between the tested samples could reside on their ability for achieving water dissociation. Thus, while $\mathrm{CO}$ activation only occurs on the Pt particle surface, water dissociation may take place either on the support or on the support and the metal particle surface. The different routes for ceria synthesis results in different concentration of oxygen vacancies in the obtained materials, and hence reduces the band gap and increases the Lewis basicity of the support. Alternatively, if the adsorptive or associative mechanism prevails, the higher concentration of oxygen vacancies is correlated with a high concentration of both active $\mathrm{C}$-containing (C-pool $\mathrm{CO}_{\mathrm{ads}}$, formates, carbonates) and $\mathrm{H}$-containing $\left(\mathrm{H}-\right.$ pool $\left.-\mathrm{H}_{2} \mathrm{O}_{\mathrm{ads}}, \mathrm{OH} / \mathrm{H}\right)$ reaction intermediates formed within a "reactive zone" around each Pt particle [56].

However, it must be taken into account that if we assume that the ability of the support for water dissociation was the same for the three $\mathrm{Pt} / \mathrm{CeO}_{2}$ catalysts (despite the differences observed), then the differences in catalytic activity can also be attributed to the $\mathrm{CO}$ adsorption properties on the Pt surface, being the $\mathrm{Pt} / \mathrm{CeO}_{2}-\mathrm{Urea}$ the sample with the best Pt dispersion. This parameter, together with the $\mathrm{Pt}-\mathrm{CeO}_{2}$ interaction, must be considered for a proper understanding of the WGS results. The TPR profiles evidenced the strongest metal-support interaction for the $\mathrm{Pt} / \mathrm{CeO}_{2}$-Urea sample since the surface reduction of ceria takes place at a lower temperature. On the other hand, the XPS results summarized in Table 3 stand that $\mathrm{Pt} / \mathrm{CeO}_{2}$-Urea catalyst shows the higher $\mathrm{Pt} / \mathrm{Ce}$ ratio, what means that this sample presents the best metallic dispersion, also corroborated by the results obtained by toluene hydrogenation. The partially occupied $f$ states of reduced cerium ions (resulting from the oxygen vacant formation where the Pt has preferential nucleation) acts as an electron donor stabilizing the Pt atoms. All of this properties account for the great activity of the $\mathrm{Pt} / \mathrm{CeO}_{2}$-Urea in the WGS reaction and make it 
suitable for the $\mathrm{CO}$ depletion even when high amounts of $\mathrm{CO}_{2}$ and $\mathrm{H}_{2}$ are included in the reactant mixtures.

Finally, according to our catalytic activity/characterization data, it must be concluded that the conventional method using urea as a precipitant agent is the best option to develop efficient $\mathrm{Pt} / \mathrm{CeO}_{2}$ catalysts for the WGS reaction.

\section{Conclusions}

This study compares three different ceria preparation procedures to develop effective $\mathrm{Pt} / \mathrm{CeO}_{2}$ catalysts for the WGS reaction. Our results clearly demonstrate that the synthesis procedure may modulate the redox and electronic properties of ceria. The type of ceria coming from the studied methods influences the posterior Pt deposition and the final features of the $\mathrm{Pt} / \mathrm{CeO}_{2}$ based catalyst. In particular, the simple and facile conventional urea-assisted homogeneous precipitation method drives to the best redox and electronic skills. Moreover, the best Pt dispersion was obtained for this solid. The Pt catalyst prepared using the urea method was superior to the $\mathrm{Pt} / \mathrm{CeO}_{2}-\mathrm{Template}$ and the $\mathrm{Pt} / \mathrm{CeO}_{2}-\mathrm{MW}$ samples. The enhanced performance of this catalyst becomes especially relevant under realistic WGS conditions.

\section{Acknowledgements}

Financial support from Generalitat Valenciana (project PROMETEOII/2014/004) and MINECO (projects MAT2013-45008-P and MAT2017-86992-R) are gratefully acknowledged. EVRF also thanks MINECO for his Ramon y Cajal fellow RYC-201211427 and the MAT2016-81732-ERC project. LPP also thanks Generalitat Valenciana for her postdoctoral fellow APOSTD2017.

\section{References}

[1] Trovarelli A, de Leitenburg C, Boaro M, Dolcetti G. Catal. Today. 1999;50:353.

[2] Montini T, Melchionna M, Monai M, Fornasiero P. Chem. Rev. 2016;116:5987.

[3] Serrano-Ruiz JC, Ramos-Fernández EV, Silvestre-Albero J, Sepúlveda-Escribano A, Rodríguez-Reinoso F. Mater. Res. Bull. 2008;43:1850. 
[4] Silvestre-Albero J, Rodríguez-Reinoso F, Sepúlveda-Escribano A. J. Catal. 2002;210:127.

[5] Yan L, Yu R, Chen J, Xing X. Cryst. Growth Des. 2008;8:1474.

[6] Hu Z, Qiu S, You Y, Guo Y, Guo Y, Wang L, Zhan W, Lu G. Appl. Catal. B: Environ. 2018;225:110.

[7] Rico-Francés S, Jardim EO, Wezendonk TA, Kapteijn F, Gascon J, SepúlvedaEscribano A, Ramos-Fernandez EV. Appl. Catal. B: Environ. 2016;180169.

[8] Vicario M, Llorca J, Boaro M, de Leitenburg C, Trovarelli A. J. Rare Earths. 2009;27:196.

[9] Ramos-Fernandez EV, Shiju NR, Rothenberg G. RSC Adv. 2014;416456.

[10] Trovarelli A. "Front Matter", in: Catalysis by Ceria and Related Materials, Published by Imperial College Press, Distributed by World Scientific Publishing Co., 2002, pp. I-XVII.

[11] Han WQ, Wu LJ, Zhou YM. J. Am. Chem. Soc. 2005;127:12814.

[12] Liu X, Zhou K, Wang L, Wang B, Li Y, J. Am. Chem. Soc. 2009;131:3140.

[13] Wu Z, Li M, Overbury H, J. Catal. 2012;285: 61.

[14] Désaunay T, Bonura G, Chiodo V, Freni S, Couzinié JP, Bourgon J, Ringuedé A, Labat F, Adamo C, Cassir M. J. Catal., 2013;297:193.

[15] Lykaki M, Pachatouridou E, Carabineiro SAC, Iliopoulou E, Andriopoulou C, Kallithrakas-Kontos N, Boghosian S, Konsolakis M. Appl. Catal. B: Environ. 2018;230:18.

[16] Gao Y, Wang W, Chang S, Huang W. ChemCatChem 2013;5:3610.

[17] Tong T, Liu X, Banis MN, Hu Y, Wang Y. J. Catal. 2018;365:420.

[18] Pastor-Pérez L, Reina TR, Ivanova S, Centeno MA, Odriozola JA, SepúlvedaEscribano A. Catalysts 2015;5:298.

[19] Gonzalez-Castaño M, Reina TR, Ivanova S, Centeno MA, Odriozola JA. J. Catal. 2014;314:1.

[20] Jain R, Poyraz AS, Gamliel DP, Valla J, Suib SL, Maric R. Appl. Catal. A: Gen. 2015;507:1. 
[21] Kalamaras CM, Americanou S, Efstahiou AM, J. Catal. 2010;279:287.

[22] Nagai $Y$, Hirabayashi $T$, Dohmae K, Takagi N, Minami T, Shinjoh H, Matsumoto S. J. Catal. 2006;242:103.

[23] Si R, Flytzani-Stephanopoulos M. Angew. Chem. Int. Ed. 2008;47:2884.

[24] Torrente-Murciano L, García-García FR. Catal. Commun. 2015;71:1.

[25] Panagiotopoulou P, Kondaries DI, Catal. Today. 2006;112:49.

[26] Orilall MC, Wiesner U, Chem. Soc. Rev. 2011;40:520.

[27] Thommes M, Kaneko K, Neimark AV, Olivier JP, Rodriguez-Reinoso F, Rouquerol J, Sing KSW. Pure Appl. Chem. 2015;87:1051.

[28] Cao C-Y, Cui Z-M, Chen C-Q, Song W-G, Cai W, J. Phys. Chem. C. 2010;114:9865.

[29] Meher SK, Rao GR, ACS Catal. 2012;2:2795.

[30] Rao KN, Bharali P, Thrimurthulu G, Reddy BM. Catal. Commun. 2010;11:863.

[31] Petrovsky V, Gorman BP, Anderson HU, Petrovsky T, J. Appl. Phys. 2001;90:2517.

[32] Marabelli F, Wachter P. Phys. Rev. B. 1987;36:1238.

[33] Rico-Francés S, Sepúlveda-Escribano A, Ramos-Fernandez EV. Int. J. Hydrogen Energy 2017;42:29262.

[34] Gonzalez Castaño M, Reina TR, Ivanova S, Centeno MA, Odriozola JA. J. Catal. 2014;314:1.

[35] Deshpande S, Patil S, Kuchibhatla SVNT, Seal S. Appl. Phys. Lett. 2005;87:133113.

[36] Tsunekawa S, Fukuda T, Kasuya A. Surf. Sci. 2000;457: L437.

[37] Acerbi N, Golunski S, Tsang SC, Daly H, Hardacre C, Smith R, Collier P. J. Phys. Chem. C. 2012;116:13569.

[38] Ho C, Yu JC, Kwong T, Mak AC, Lai S. Chem. Mater. 2005;17:4514.

[39] Huang XS, Sun H, Wang, LC, Liu YM, Fan KN, Cao Y. Appl. Catal. B 2009;90: 224. 
[40] Jardim EO, Rico-Francés S, Coloma F, Ramos-Fernández EV, Silvestre-Albero J, Sepúlveda-Escribano A. Appl. Catal. A: Gen. 2014;487:119.

[41] Zhibo R, Fei P, Jianwei L, Xin L, Biaohua C, Catalysts 2017;7:48.

[42] Connie MY, YeungKai MK. Yu Qi J, Fu D, Thompsett MI, Petch S, Chi T. J. Am. Chem. Soc.2005;127:51:18010.

[43] Buitrago-Sierra R, Serrano-Ruiz JC, Rodríguez-Reinoso F, Sepúlveda-Escribano A, Dumesic JA. Green Chem. 2012:14:3318.

[44] Abdelouahab-Reddam Z, El Mail R, Coloma F, Sepúlveda-Escribano A. Catal. Today. 2015;249:109.

[45] Sepúlveda-Escribano A, Coloma F, Rodríguez-Reinoso F. J. Catal. 1998;178:649.

[46] Moretti E, Storaro L, Talon A, Riello P, Molina AI, Rodríguez-Castellón E., Appl. Catal. B: Environ. 2015;168-169:385.

[47] Trovarelli A, Dolcetti G, De Leitenburg C, Kašpar J, Finetti P, Santoni A. J. Chem. Soc. Faraday Trans. 1991;88:1311.

[48] Kundu S, Ciston J, Senanayake SD, Arena DA, Fujita E, Stacchiola D, Barrio L, Navarro RM, Fierro JLG, Rodriguez JA. J. Phys. Chem. C. 2012;116:14062.

[49] Senanayake SD, Rodriguez JA, Stacchiola D. Top. Catal. 2013;56:1488.

[50] Ramos-Fernández EV, Ramos-Fernández JM, Martínez-Escandell M, SepúlvedaEscribano A, Rodríguez-Reinoso F. Catal. Letters. 2009;133:267.

[51] Goguet A, Meunier F, Breen JP, Burch R, Petch MI, Faur Ghenciu A. J. Catal. 2004;226:382.

[52] Serrano-Ruiz JC, Luettich J, Sepúlveda-Escribano A, Rodríguez-Reinoso F. J. Catal. 2006;241: 45.

[53] Farrauto RJ, Liu Y, Ruettinger W, Ilinich O, Shore L, Giroux T. Catal. Rev. 2007;49:141.

[54] Reina TR, Ivanova S, Laguna OH, Centeno MA, Odriozola JA. Appl. Catal. B: Environ. 2016;197:67.

[55] Reina TR, Ivanova S, Delgado JJ, Ivanov I, Idakiev V, Tabakova T, Centeno MA, Odriozola JA. ChemCatChem 2014;6:1401. 
[56] Petallidou KC, Kalamaras CM, Efstahiou AM, Catal. Today. 2014;228:183. 


\title{
Effect of the $\mathrm{CeO}_{2}$ synthesis method on the behaviour of $\mathrm{Pt} / \mathrm{CeO}_{2}$ catalysis for the water-gas shift reaction
}

\author{
L. Pastor-Pérez, E.V. Ramos-Fernández and A. Sepúlveda-Escribano* \\ Laboratorio de Materiales Avanzados, Departamento de Química Inorgánica - Instituto \\ Universitario de Materiales de Alicante. Universidad de Alicante. Apartado 99, E-03080 \\ Alicante, Spain.
}

\begin{abstract}
A comparative study of three different ceria synthesis procedures (template- and MWassisted hydrothermal synthesis and urea homogeneous precipitation) is reported in this paper. The obtained materials were employed as supports for Pt nanoparticles, and the $\mathrm{Pt} / \mathrm{CeO}_{2}$ catalysts were evaluated in the WGS reaction under model and realistic conditions. The influence of the support, e.g., its morphology and electronic properties, has been studied in detail by means of XRD, $\mathrm{H}_{2}$-TPR, XPS, UV-Vis spectroscopy and toluene hydrogenation (for metal dispersion assessment). The catalytic performance of the samples is directly correlated with the modification of the electronic properties, as a result of the preparation method used. The conventional homogeneous precipitation method with urea resulted to be the best option, leading to enhanced ceria reducibility and adequate Pt dispersion, which in turns resulted in a very efficient WGS catalyst.
\end{abstract}

Keywords: $\mathrm{Pt} / \mathrm{CeO}_{2}$; urea precipitation; microwave-assisted synthesis; polymer-assisted synthesis; WGS. 


\section{Introduction}

Cerium oxide (ceria, $\mathrm{CeO}_{2}$ ) is one of the most abundant rare-earth oxides, and it is very important in many catalytic processes where it is used as support for an active phase or by catalyst by itself $[1,2]$. Thus, it is an important component in the formulation of the three ways catalysts (TWCs) which are used to abate the toxic emissions of Otto engines [1,3], and also in Diesel engines, where it promotes the combustion of soot particles. Other emerging catalytic processes in which cerium oxides are been used are the oxidation of volatile compounds, reforming reactions, hydrogenation and hydrogenolysis reactions and water-gas shift, among others.

It is well recognized in the literature that the oxide's morphology is an important structural factor that can affect its chemical properties and, thus, its catalytic performance [1, 4-6]. In this sense, the surface composition and structure of $\mathrm{CeO}_{2}$ can greatly affect the nature and extent of the interaction between the active phase and its surface, when it is used as support for metal catalysts [7]. It has to be taken into account that the application of $\mathrm{CeO}_{2}$ as catalyst or catalyst support is mainly related to its surface reducibility, with the consequent formation of surface vacancies, which makes it a redox buffer [8]. This unique feature of ceria is termed as oxygen storage capacity (OSC), and it derives from the ability to be easily and reversibly reduced to several $\mathrm{CeO}_{2-\mathrm{x}}$ stoichiometries when it is exposed to $\mathrm{O}_{2}$ deficient atmospheres [9,10]. And it seems that this ability may depend on the oxide morphology, as different exposed surfaces may have different redox behaviours and interactions with the active phase. The most common method of ceria synthesis, precipitation from a cerium precursor solution by increasing the $\mathrm{pH}$, yields nanocrystals with irregular morphologies that expose several kinds of crystal planes. Such morphological complexity and inhomogeneity make it difficult to investigate and understand the effect of the $\mathrm{CeO}_{2}$ crystal`s morphology in the behaviour of ceria-supported catalysts. Consequently, a lot of work has been devoted to developing synthesis methods that allow preparing ceria particles with different morphologies and sizes [5].

Han et al. used a mild hydrothermal route to prepare ceria nanotubes, using ammonia solution as precipitation agent at large ageing times [11]. Liu et al. prepared ceria nanorods, also following a hydrothermal method, with different types and distributions of oxygen vacancies [12]. Some years later, $\mathrm{Wu}$ et al. investigated the catalytic behaviour of different ceria crystal surfaces in the $\mathrm{CO}$ oxidation reaction. To 
this end, they prepared ceria nanorods, nanocubes and octahedra, and observed different behaviours that were related to differences in the energetics of formation of surface oxygen vacancies, in such a way the reactivity for $\mathrm{CO}$ oxidation increased following the trend: rods > cubes > octahedra [13]. Désaunay et al. determined the surface dependency of hydrogen oxidation on ceria nanocrystals with different shapes exposing different surface planes: nanocubes exposing only (100) surfaces, octahedral exposing only (111) surfaces and nanorods exposing at least $50 \%$ of (110) surfaces [14]. The effect of the ceria particle shape on the interaction with a supported active phase has also been evidenced by several authors. Thus, the effect of the ceria particles shape in $\mathrm{Cu} / \mathrm{CeO}_{2}$ catalysts for $\mathrm{CO}$ oxidation has been recently studied by Lykaki et al. They observed the activity trend rods > polyhedral > cubes, which was the same for both ceria and $\mathrm{Cu} /$ ceria catalysts, and assigned this effect to the higher ability for the stabilization of $\mathrm{Cu}^{+}$species [15]. The effect of the ceria support has also been studied in platinum-based catalysts for different reactions. Thus, Gao et al. observed a strong morphology effect in platinum supported on ceria rods, cubes and octahedral in the preferential oxidation of $\mathrm{CO}$ in a $\mathrm{H}_{2}$-rich stream (CO-PROX), which they correlated with the exposed crystal planes [16]. Tong et al. also observed a very important effect of the ceria crystal planes exposed in Pt/ceria catalysts for the hydrogenolysis of furfuryl alcohol to 1,2-pentanediol [17]. In this case, they concluded that the reaction selectivity was determined by the chemical state of platinum, which was in turn controlled by the extent of the metal-support interaction with the ceria surface via the oxygen vacancies. The best catalytic performance was obtained in the Pt/ceria nanocube system exposing the (100) ceria surface.

One of the potential applications of ceria as support is in the preparation of catalysts for the water-gas shift reaction that it is used for balancing the $\mathrm{H}_{2} / \mathrm{CO}$ ratio in reforming streams $\left(\mathrm{CO}+\mathrm{H}_{2} \mathrm{O} \rightarrow \mathrm{CO}_{2}+\mathrm{H}_{2}\right)$ [18-20]. It provides a source of hydrogen at the expenses of carbon monoxide, which is also important for the production of high purity hydrogen. Specifically, the use of ceria as support contributes to the WGS reaction by facilitating the redox process, as it provides activated oxygen to oxidize the $\mathrm{CO}$ adsorbed on the metal. However, the effect of the support characteristics and how they affect the catalytic behaviour in this reaction is usually relegated to a second plane or not even mentioned. 
As an example, one of the critical factors, together with the redox properties of the ceria support, is the dispersion of Pt on the support, which also depends on the ceria surface chemistry. It has been shown that the interaction between Pt and ceria-based oxides can inhibit Pt growth and sintering. Previous studies by Efstathiou et al, reported that Pt particle size has an effect on the intrinsic WGS kinetic rate [21]. Furthermore, the Pt-Ce interaction can result in a synergic effect, improving the catalytic activity [22].

Si and Flytzani-Stephanopoulos prepared gold nanoparticles supported on ceria nanorods, nanocubes and nanopolyhedra, and they observed a strong effect of ceria shape on the catalytic activity for the water-gas shift (WGS) reaction, being gold supported on the (110) surface of ceria nanorods the most active catalyst [23]. However, there are very few studies on the effect of ceria morphology in Pt-based catalysts for WGS. One of the latest is the work by Torrente-Murciano and García-García, who studied the catalytic behaviour in WGS of Pt/ceria catalysts using supports with different morphologies (rods, cubes and irregular nanoparticles). They showed that the best results in terms of hydrogen yield and low methane selectivity were obtained when ceria nanorods were used and claimed that it was related to the preferential exposure of the (110) crystal plane [24]. Despite that there is not much information in the literature, there are some discrepancies on this possible support morphology effect. Kondaries et al. concluded that activity of $\mathrm{Pt} / \mathrm{CeO}_{2}$ does not depend on the structural and morphological characteristics of the support, at least in the range of surface areas (3.3$\left.57 \mathrm{~m}^{2} / \mathrm{g}\right)$ and primary crystallite sizes $(10-32 \mathrm{~nm})$ they tested [25].

Based on the above, in this work we have tried to deepen in the different properties that can be achieved through the preparation of $\mathrm{CeO}_{2}$ supports employing different synthesis methods, and carried out a thorough comparison in their behaviour when they are used as catalysts in the water-gas shift reaction. Irregular $\mathrm{CeO}_{2}$ nanoparticles were prepared by a simple and facile conventional precipitation method. In order to investigate the effect of the structure and morphology of $\mathrm{CeO}_{2}$ in the catalytic performance, two more methods to obtain controlled surface morphology/structure of $\mathrm{CeO}_{2}$ were chosen: a fast template-free method assisted by microwaves and a template (polymer)-assisted method under hydrothermal conditions. In addition, the effect of the $\mathrm{Pt}$ dispersion and $\mathrm{Pt}-\mathrm{CeO}_{2}$ interactions on different ceria supports was investigated. Different catalytic performances of these $\mathrm{Pt} / \mathrm{CeO}_{2}$ samples in the water-gas shift reaction (WGS) were obtained. 


\section{Experimental}

\section{Catalysts preparation}

Three $\mathrm{CeO}_{2}$ supports were prepared employing different synthesis methods. For $\mathrm{CeO}_{2}$-Urea, homogeneous precipitation with urea was used. Thus, an aqueous solution of $\mathrm{Ce}\left(\mathrm{NO}_{3}\right)_{3} \cdot 6 \mathrm{H}_{2} \mathrm{O}(99.99 \%$, Sigma-Aldrich) containing an excess of urea was heated at $80{ }^{\circ} \mathrm{C}$ and kept at this temperature, with smooth stirring, for $12 \mathrm{~h}$. The solid formed was filtered and calcined at $350{ }^{\circ} \mathrm{C}$ for $4 \mathrm{~h}$.

$\mathrm{CeO}_{2}-\mathrm{MW}$ was prepared by microwave-assisted hydrothermal synthesis. A certain amount of $\mathrm{Ce}\left(\mathrm{NO}_{3}\right)_{3} \cdot 6 \mathrm{H}_{2} \mathrm{O}(99.99 \%$, Sigma-Aldrich) and the required amount of urea were dissolved in water. The reaction solution was poured into a Teflon-lined autoclave which was sealed and placed into a programmable microwave oven (Milestone, Ethos One). The oven was heated to $170{ }^{\circ} \mathrm{C}$ in $2 \mathrm{~min}$ and then kept at this temperature for 30 minutes by microwave irradiation. After cooling to room temperature, the sample was filtered and dried. Finally, the solid was calcined during 4 $\mathrm{h}$ at $350^{\circ} \mathrm{C}$.

Finally, a polymer-assisted hydrothermal synthesis was used for the preparation of $\mathrm{CeO}_{2}$-Template. In this route, the corresponding amount of $\mathrm{Ce}\left(\mathrm{NO}_{3}\right)_{3} \cdot 6 \mathrm{H}_{2} \mathrm{O}(99.99 \%$, Sigma-Aldrich), $2.9 \mathrm{mmol}$ of $\mathrm{CeO}_{2}$, was dissolved in water, and the resulting solution was added to an aqueous solution containing $0.15 \mathrm{mmol}$ P123 (poly(ethylene glycol)poly(propylene glycol)-poly(ethylene glycol) (P123, Sigma-Aldrich) with a molecular weight of $5800 \mathrm{~g}$. The solution was homogenized by stirring for $1 \mathrm{~h}$ and then, $0.8 \mathrm{mmol}$ of urea was added and the solution was stirred again for $3 \mathrm{~h}$. The final solution was then transferred to a stainless steel autoclave with an inside Teflon liner and subjected to heating at $120^{\circ} \mathrm{C}$ for $24 \mathrm{~h}$. The autoclave was then allowed to cool to room temperature, and after ageing the resultant product for $24 \mathrm{~h}$, the solid was filtered and repeatedly washed with distilled water. After drying in an oven at $100{ }^{\circ} \mathrm{C}$, the solid was treated at $350{ }^{\circ} \mathrm{C}$ for $4 \mathrm{~h}$ under flowing $\mathrm{He}(50 \mathrm{~mL} / \mathrm{min})$.

$\mathrm{CeO}_{2}$-supported $\mathrm{Pt}$ catalysts were prepared by impregnation by an excess of solvent. The corresponding amount of $\mathrm{H}_{2} \mathrm{PtCl}_{6} \cdot 6 \mathrm{H}_{2} \mathrm{O}(99.99 \%$, Alfa Aesar) was dissolved in acetone to obtain catalysts with $1 \mathrm{wt}$.\% Pt. Calcined $\mathrm{CeO}_{2}$ was added to the solution, in a proportion of $10 \mathrm{~mL} / \mathrm{g}$ of support, with stirring. After $12 \mathrm{~h}$, the excess of 
solvent was slowly removed under vacuum and then dried in the oven until complete removal of the solvent. Finally, the solids were calcined $4 \mathrm{~h}$ at $350{ }^{\circ} \mathrm{C}$. The three prepared catalysts are labelled as $\mathrm{Pt} / \mathrm{CeO}_{2}-\mathrm{Urea}, \mathrm{Pt}-\mathrm{CeO}_{2}-\mathrm{Microwave}$ and $\mathrm{Pt}-\mathrm{CeO}_{2}$ Template.

\section{Catalysts characterization}

The textural properties of the supports were characterized by nitrogen adsorption measurements at $-196^{\circ} \mathrm{C}$. Gas adsorption experiments were performed in a home-made fully automated volumetric equipment. Prior to the adsorption experiments, samples were out-gassed under vacuum $\left(10^{-4} \mathrm{~Pa}\right)$ at $250{ }^{\circ} \mathrm{C}$ for $4 \mathrm{~h}$. The "apparent" surface area was estimated after application of the BET equation.

The actual metal loading of the different catalysts was determined by ICP-OES in a Perkin-Elmer device (Optimal 3000). To this end, the metal was extracted from the catalysts by digestion in aqua regia for $30 \mathrm{~min}$ in a microwave oven (Milestone, Ethos One) at $180{ }^{\circ} \mathrm{C}$.

X-Ray powder diffraction patterns were recorded on a Bruker D8-Advance with a Göebel mirror and a Kristalloflex K 760-80 F X-Ray generation system, fitted with a $\mathrm{Cu}$ cathode and a Ni filter. Spectra were registered between 20 and $80^{\circ}(2 \theta)$ with a step of $0.05^{\circ}$ and a time per step of $3 \mathrm{~s}$.

Scanning electron microscopy (SEM) and the semi-quantitative elemental analysis was obtained by energy dispersive X-ray spectroscopy (EDS). SEM/EDS analyses were performed on a JEOL JSM 35C/Noran Voyager system.

TEM observations were carried out on a JEOL electron microscope (model JEM-2010) working at $200 \mathrm{kV}$. It was equipped with an INCA Energy TEM 100 analytical system and a SIS MegaView II camera. Samples for analysis were suspended in ethanol and placed on copper grids with a holey-carbon film support.

Electronic modification (Band gap) of the solids was analysed with an integrating sphere ISV-722 UV-Visible containing the Jasco V-650 M, a double-beam spectrophotometer with a photomultiplier tube detector.

Temperature-programmed reduction (TPR) with $\mathrm{H}_{2}$ measurements were carried out on calcined catalysts in a U-shaped quartz cell using a $5 \% \mathrm{H}_{2} / \mathrm{He}$ gas flow of 50 
$\mathrm{mL} / \mathrm{min}$, with a heating rate of $10^{\circ} \mathrm{C} / \mathrm{min}$. Samples were treated with flowing He at 150 ${ }^{\circ} \mathrm{C}$ for $1 \mathrm{~h}$ before the TPR run. Hydrogen consumption was followed by on-line mass spectrometry.

X-Ray photoelectron spectroscopy was performed with a K-ALPHA spectrometer (Thermo Scientific). All spectra were collected using Al-K $\alpha$ radiation $(1486.6 \mathrm{eV})$, monochromatized by a twin crystal monochromator, yielding a focused $\mathrm{X}$ ray spot with a diameter of 400_m, at $3 \mathrm{~mA} \times 12 \mathrm{kV}$. The alpha hemispherical analyser was operated at the constant energy mode with survey scan pass energies of $200 \mathrm{eV}$ to measure the whole energy band and $50 \mathrm{eV}$ in a narrow scan to selectively measure the particular elements. Charge compensation was achieved with the system flood gun that provides low energy electrons and low energy argon ions from a single source. The powder samples were pressed and mounted on the sample holder and placed in the vacuum chamber. Before recording the spectrum, the samples were maintained in the analysis chamber until a residual pressure of ca. $5 \times 10^{-7} \mathrm{~N} \cdot \mathrm{m}^{-2}$ was reached. The quantitative analysis was estimated by calculating the integral of each peak, after subtracting the S-shaped background, and by fitting the experimental curve to a combination of Lorentzian (30\%) and Gaussian (70\%) lines.

\section{Catalytic behaviour}

Two different catalytic reactions have been used with the $\mathrm{Pt} / \mathrm{CeO}_{2}$ catalysts to investigate the effect of the structure and morphology of the different $\mathrm{CeO}_{2}$ supports prepared, toluene hydrogenation and water-gas shift (WGS).

The catalytic behaviour of the catalysts in the toluene hydrogenation reaction has been used to estimate differences in Pt dispersion in the different catalysts. This reaction has a structure-insensitive character, which makes the catalytic activity to depend only on the number of metallic sites available at the surface. The catalytic activity of the prepared catalysts was compared to the activity of a commercial one ( $\mathrm{Pt} / \mathrm{Al}_{2} \mathrm{O}_{3}$, Sigma Aldrich) whose metallic dispersion has been accurately determined by TEM analysis, using the following equation:

$$
D=\frac{6 \cdot V_{m}}{a_{m} \cdot d V_{A}}
$$


where $\mathrm{dV}_{\mathrm{A}}$ is the average diameter of Pt particles (measured by TEM), $\mathrm{a}_{\mathrm{m}}$ is the area per Pt atom on the surface, $\mathrm{a}_{\mathrm{m}}=\pi \mathrm{r}_{\mathrm{Pt}}{ }^{2} ; \mathrm{V}_{\mathrm{m}}$ is the Pt atomic volume, $\mathrm{V}_{\mathrm{m}}=(4 \pi / 3) \mathrm{r}_{\mathrm{Pt}}{ }^{3}$, and $\mathrm{r}_{\mathrm{Pt}}=$ $1.38 \cdot 10^{-10} \mathrm{~cm}$.

Toluene hydrogenation tests were performed in a U-shape quartz reactor at atmospheric pressure, and the products were monitored by on-line gas chromatograph $($ Agilent $6890 \mathrm{~N})$ with a flame ionization detector and HP-Plot/Q $(30 \mathrm{~m} \times 0.53 \mathrm{~mm})$ column. Prior to reaction, the samples $(20 \mathrm{mg})$ were reduced in situ at $350{ }^{\circ} \mathrm{C}$ for $2 \mathrm{~h}$ under flowing hydrogen $(50 \mathrm{~mL} / \mathrm{min})$. The reaction was evaluated at $60{ }^{\circ} \mathrm{C}$, with a total flow of $50 \mathrm{~mL} / \mathrm{min}$ containing hydrogen and toluene in $\mathrm{H}_{2} / \mathrm{C}_{7} \mathrm{H}_{8}$ ratio of 36 , obtained by passing the hydrogen flow through a thermos-stabilized saturator containing toluene at $20^{\circ} \mathrm{C}$.

The catalytic behaviour of the prepared samples in the low-temperature watergas shift reaction was evaluated in a fixed bed flow reactor under atmospheric pressure in the range of temperatures from 160 to $360{ }^{\circ} \mathrm{C}$. Two different feed gas mixtures were used, both of them with a total flow of $100 \mathrm{~mL} / \mathrm{min}$. The idealized feed gas mixture contained $5 \% \mathrm{CO}$ and $30 \mathrm{~mol} \% \mathrm{H}_{2} \mathrm{O}$ in $\mathrm{He}$; on the other hand, trying to simulate a closer to actual outgas mixture from a reformer, experiments with a feed gas composition of $7 \mathrm{~mol} \% \mathrm{CO}, 30 \mathrm{~mol} \% \mathrm{H}_{2} \mathrm{O}, 50 \mathrm{~mol} \% \mathrm{H}_{2}$, and $9 \mathrm{~mol} \% \mathrm{CO}_{2}$ in helium were carried out. Activity tests were performed using $0.150 \mathrm{~g}$ of catalyst diluted with $\mathrm{SiC}$, to avoid thermal effects. The corresponding WHSV was $40000 \mathrm{~mL} / \mathrm{g} \cdot \mathrm{h}$. Prior to reaction, the catalysts were reduced under flowing $\mathrm{H}_{2}(50 \mathrm{~mL} / \mathrm{min})$ for $2 \mathrm{~h}$ at $350{ }^{\circ} \mathrm{C}$. The composition of the gas stream exiting the reactor was determined by mass spectrometry (Pfeiffer, OmniStar GSD 301), and the catalytic activity will be expressed by degree of $\mathrm{CO}$ conversion as a function of the reaction temperature. The stabilization time for each temperature was $1 \mathrm{~h}$ and the $\mathrm{CO}$ conversion percentage was calculated by this equation:

$$
\mathrm{CO} \text { conversion }(\%)=100-\left(x \mathrm{CO} / x \mathrm{CO}_{\text {initial }}\right) \cdot 100
$$

where $x \mathrm{CO}$ is the concentration of $\mathrm{CO}$ in the outlet of the reactor and $x \mathrm{CO}_{\text {initial }}$ is the $\mathrm{CO}$ concentration in the initial gas mixture. The carbon balance was checked taking into account all the carbon-containing products.

\section{Results and discussion}




\section{Catalysis characterization}

The powder X-ray diffraction (XDR) patterns of the $\mathrm{CeO}_{2}$ supports after the calcination treatment are shown in Fig. 1. The characteristic $\mathrm{CeO}_{2}$ peaks (JCPDS 340394, space group Fm3m) at 28.6, 33.4, 47.8, 56.7, 59.1, 69.4, 76.7, and 79.1 ${ }^{\circ}$, corresponding to reflections in the (111), (200), (220), (331), (222), (400), (331), (420) and (422) crystalline planes of the cubic fluorite-type phase respectively, can be clearly observed. By application of the Scherrer equation to the (111) diffraction peak, the mean crystal sizes of $\mathrm{CeO}_{2}$ in the different supports have been determined, and they are presented in the table inserted in Fig. 1. The $\mathrm{CeO}_{2}$-Template support presents the lowest crystallite size $(9.3 \mathrm{~nm})$. It is known that the selective surface adsorption properties of P123 prevent agglomerations, frenzied crystal growth, and structural disorganization of nascent crystallites [26]. Regarding microwave and urea synthesis, they lead to a similar ceria particle size of ca. $12 \mathrm{~nm}$.

XRD profiles of $\mathrm{Pt} / \mathrm{CeO}_{2}$ catalysts (not shown) only exhibit the peaks that belong to the $\mathrm{CeO}_{2}$ phase, whereas no diffraction peaks belonging to Pt species could be detected. This indicates that the dispersion of the metallic particles over the $\mathrm{CeO}_{2}$ supports occurred presumably without the formation of large crystalline particles.

Table 1 shows the specific surface area $\left(\mathrm{N}_{2},-196{ }^{\circ} \mathrm{C}\right.$, BET), the micropore volume $\left(\mathrm{V}_{\text {micro }}, \mathrm{N}_{2},-196{ }^{\circ} \mathrm{C}, \mathrm{D}-\mathrm{R}\right)$ and the volume of mesopores $\left(\mathrm{V}_{\text {meso }}\right)$ for the three supports, as well as the actual Pt loading (ICP analysis) of the three catalysts. The $\mathrm{N}_{2}$ adsorption isotherms at $-196{ }^{\circ} \mathrm{C}$ for all supports (Fig. 2) correspond to a combination of Type I and Type IV isotherms (according to the IUPAC classification) [27], showing the presence of some microporosity (steep increase of the amount adsorbed at very low relative pressure) and a small contribution of mesopores (hysteresis loop) mostly formed by particle agglomeration, as inter-particle porosity. Regarding $\mathrm{CeO}_{2}-\mathrm{MW}$, the higher contribution of mesopores in this sample is very likely due to the void space among the stacked hollow spheres [28]. In contrast, the lack of any defined morphology favouring a more compact agglomeration of particles could be the reasons behind the lower mesoporosity in the $\mathrm{CeO}_{2}$-Urea sample [29].

Finally, the actual $\mathrm{Pt}$ content of the catalysts was determined by ICP measurements, and the results are reported in Table 1. The obtained values match the nominal ones, confirming the successful Pt deposition. 
The surface morphological characteristics of the calcined $\mathrm{CeO}_{2}$ samples were investigated by SEM and TEM analysis (Fig. 3). The $\mathrm{CeO}_{2}$-Urea sample shows a typical SEM image of polyhedrical $\mathrm{CeO}_{2}$ particles. During the urea homogeneous precipitation process, the kinetically slow nucleation of $\mathrm{Ce}^{3+}$ with the increasing of the $\mathrm{pH}$ due to the formation of $\mathrm{OH}^{-}$and $\mathrm{CO}_{3}{ }^{2-}$ ions (from the hydrolysis and decomposition of urea) produces $\mathrm{Ce}_{2} \mathrm{O}-\left(\mathrm{CO}_{3}\right)_{2} \cdot \mathrm{H}_{2} \mathrm{O}$ and $\mathrm{Ce}(\mathrm{OH})_{3}$ seeds, followed by nanocrystals. The coalesced/ripened nanocrystals undergo random growth under thermal conditions (calcination), leading to the formation of heterogeneous polyhedra-like microcrystals [28]. However, the $\mathrm{CeO}_{2}-\mathrm{MW}$ and $\mathrm{CeO}_{2}$-Template samples show a well-defined and structured morphology in contrast to the $\mathrm{CeO}_{2}$-Urea. The SEM image of $\mathrm{CeO}_{2}-\mathrm{MW}$ support (Fig. 3.A1) shows that nearly monodispersed (in size) nanospheres are obtained. A closer examination by TEM indicates that the entire structure of the sphere consists of many small nanoparticles (Fig. 3.A2). An Ostwald ripening coupled self-templated, self-assembly process for the formation of the $\mathrm{CeO}_{2}$ hollow nanospheres is proposed [28]. For the $\mathrm{CeO}_{2}$-Template support, the grain/ripened nanocrystals under selective crystal-facet adhesion of polymer molecules undergo kinetic shape control, producing rod-shape structures [29]. It is worth to mention that these three differently shaped ceria nanoparticles maintain their original shapes after platinum deposition (not shown).

The electronic properties of the studied supports and catalysts were obtained by UV-Vis spectroscopy analysis. The UV-Vis spectra of all samples are shown in Fig. 4. All the samples presented the characteristic absorption region associated with $\mathrm{CeO}_{2}$ and assigned to a charge transfer $\mathrm{O}_{2 p} \rightarrow \mathrm{Ce}_{4 f}$ transition. Two bands can be seen for all $\mathrm{CeO}_{2}$ samples with different morphologies at about $277 \mathrm{~nm}$, corresponding to an $\mathrm{O}^{2-} \rightarrow \mathrm{Ce}^{4+}$ charge transfer, and at $347 \mathrm{~nm}$, attributed to inter-band transitions [30]. Furthermore, the absorption band at $255 \mathrm{~nm}$, corresponding to an $\mathrm{O}^{2-} \rightarrow \mathrm{Ce}^{3+}$ charge transfer, could be intuited.

For further understanding, indirect band gaps of the samples were estimated by the Kubelka-Munk function, and are listed in Table 2. The band gaps obtained for the three ceria supports are smaller than that found in ceria single crystals $(3.02 \mathrm{eV})[31,32]$. The experimental band structure of $\mathrm{CeO}_{2}$ is described considering the valence and conduction bands from $\mathrm{O}_{2 p}$ and $\mathrm{Ce}_{5 d}$ states, respectively, separated ca. $6 \mathrm{eV}$. Between these two bands, the $\mathrm{Ce}_{4 f}$ band appears. For defect-free crystals, the later is empty and lies around ca. $3 \mathrm{eV}$ above the valence band, but if it becomes partially occupied, their 
energy separation with the valence band decreases. The $\mathrm{Ce}_{4 f}$ band becomes partially occupied when $\mathrm{Ce}^{3+}$ is present. So, the reduction of the band gap is associated with the presence of $\mathrm{Ce}^{3+}$ that enhances the photon absorption in the visible region $[7,33]$. This description results in a fairly localized picture of the $4 \mathrm{f}$ electrons that remain on the cerium ions resulting in $\mathrm{Ce}^{3+}$ ions [34]. The reason for this red-shift band gap in our $\mathrm{CeO}_{2}$ samples must be associated with the higher ratio of $\mathrm{Ce}^{3+}$ to $\mathrm{Ce}^{4+}$ species. As the $\mathrm{Ce}^{3+}$ ions concentration increases, a decrease in the band gap is observed [35,36]. This is associated with the population of the defect state, oxygen vacancies and the presence of partially reduced ceria on the catalysts surface, as reported elsewhere [24]. Besides, the difference in the concentration of $\mathrm{Ce}^{3+}$ ions can be attributed to the different morphologies [38]. These surface defects such as oxygen vacancies can prevent hole-electron recombination, working as electron traps, and can also act as strong binding and dissociation sites for adsorbates [39]. Considering the three $\mathrm{CeO}_{2}$ samples, the lowest band gap was obtained for the $\mathrm{CeO}_{2}$-Urea support, this evidencing the higher population of $\mathrm{Ce}^{3+}$ ions and oxygen vacancies in this sample [40]. Some studies reported that the difference in the $\mathrm{Ce}^{3+}$ contents are originated from the exposed surface planes of the $\mathrm{CeO}_{2}$ supports; concretely, the desorption of oxygen occurs more easily for the (100) and (110) surfaces than for the most stable (111) planes [41]. Therefore, these results indicated that the different morphologies of the $\mathrm{CeO}_{2}$ supports can result in different coordination environments of the supported Pt particles.

Additionally, the UV-Vis spectra and the band gap of the $\mathrm{Pt} / \mathrm{CeO}_{2}$ catalysts are also shown in Fig. 4 and Table 2, respectively. It can be observed that Pt remarkably reduces the material's band gap, this suggesting the insertion of metal levels between the valence and conduction bands of ceria and pointing to a strong metal-support interaction [35]. In addition, the enhanced ceria reducibility due to the intimate Pt-ceria contact may induce band gap contraction, as previously observed [37]. These data suggest that an electron transfer process may take place at the interface between ceria and metal "in facilitating the redox properties of the ceria" [42]. It is also remarkable that the catalyst prepared by using the urea-assisted method shows the lowest band gap [43].

$\mathrm{H}_{2}$-TPR measurements were employed in order to assess the redox properties of the supports and catalysts; the obtained TPR profiles are presented in Fig. 5. TPR 
profiles of supports are rather similar, and only two peaks are shown at 450 and $800{ }^{\circ} \mathrm{C}$, which are associated with the reduction of surface and bulk ceria, respectively $[33,35]$.

Fig. 5B shows the TPR profiles obtained with the catalysts, which are similar to those reported in the literature for Pt-ceria systems [44-47]. The first intense peak centred at low temperatures is assigned to the surface reduction of ceria in close contact with the metal, as well as the platinum reduction (breakdown of $\mathrm{Pt}-\mathrm{O}-\mathrm{CeO}_{2}$ species created upon calcination). In addition, the presence of Pt shifted the ceria surface reduction process towards lower temperatures, evidencing the metal phase-support intimacy, which promotes ceria reducibility. This effect agrees with previous studies on $\mathrm{Pt} / \mathrm{CeO}_{2}$ catalysts [48, 49]. The second peak (not shown, and located at high temperatures between 600 and $900{ }^{\circ} \mathrm{C}$ ) is ascribed to the $\mathrm{CeO}_{2}$ bulk reduction. However, further analysis reveals that our samples present different TPR profiles. For the $\mathrm{Pt} / \mathrm{CeO}_{2}$-Urea catalysts, the first peak appears at lower temperatures than the peak for their counterparts, this pointing to higher oxygen mobility in this sample. Presumably, the enhanced oxygen mobility of this sample is related to the higher population of oxygen vacancies in the sample (as shown by UV analysis) and/or to a better platinum dispersion inducing a maximized $\mathrm{Pt}-\mathrm{CeO}_{2}$ interaction. On the other hand, the peak at a lower temperature for the $\mathrm{Pt} / \mathrm{CeO}_{2}$-Template catalyst has a smaller area, and the presence of two overlapped peaks is noticed. The poorer hydrogen consumption indicates a lower ceria reduction degree, what can be assigned to smaller $\mathrm{Pt}-\mathrm{CeO}_{2}$ interface which could be related to larger Pt particles. The presence of two reduction peaks also suggests different $\mathrm{Pt}-\mathrm{CeO}_{2}$ interactions. The $\mathrm{Pt} / \mathrm{CeO}_{2}-\mathrm{MW}$ sample presents only one reduction process at approximately the same temperatures than that of the $\mathrm{Pt} / \mathrm{CeO}_{2}-\mathrm{Template}$ catalyst.

In order to assess the dispersion and the chemical state of $\mathrm{Pt}$ on the ceria supports, the reduced samples have been analyzed by XPS. The catalysts were reduced ex-situ at $350{ }^{\circ} \mathrm{C}$ under flowing $\mathrm{H}_{2}$ and conserved in octane until the analysis. The binding energies (B.E.) of the $\mathrm{Pt}^{0} 4 f_{7 / 2}$ core level, the surface $\mathrm{Pt} / \mathrm{Ce}$ atomic ratio and the surface $\mathrm{Ce}^{3+}$ content $(\%)$ are summarized in Table 3. Fig. 6 shows the XPS spectra of the Pt $4 f$ core level. The spectrum of the $\mathrm{Pt} / \mathrm{CeO}_{2}$-Urea sample has two well-defined peaks that are ascribed to the spin-orbit component of the $\mathrm{Pt} 4 f$ level. The peaks are centred at $72.7 \mathrm{eV}\left(\mathrm{Pt} 4 f_{7 / 2}\right)$ and at $75.9 \mathrm{eV}\left(\mathrm{Pt} 4 f_{5 / 2}\right)$. It means that there is only one type of Pt species. The other two samples show different spectra, which in both cases can be 
deconvoluted in four peaks indicating that there are two platinum species in these samples. In order to simplify the discussion, for now on we will focus on the $4 f_{7 / 2}$ level [50]. Coming back to the urea-based sample, the $4 f_{7 / 2}$ peak is located at $72.7 \mathrm{eV}$ and can be ascribed to oxidic platinum species. If we look up the TPR profile of this sample (Fig. 5), the platinum particles should be reduced during the hydrogen pretreatment. We think that the platinum species generated in this catalyst are strongly interacting with the support that actually has more oxygen vacancies. In fact, the TPR results indicate that the oxygen vacancies are generated at a lower temperature in this catalyst, which is also demonstrated by the UV-Vis analysis. The presence of these oxygen vacancies, together with the high platinum-support interaction, induces an electronic transfer where platinum particles tend to maintain some positive charge and to increase ceria reducibility. It can be seen in Table 3 that the binding energies of the $\mathrm{Pt} 4 f$ core level spectra shift to lower values in the following order: $\mathrm{Pt} / \mathrm{CeO}_{2}-\mathrm{Urea}>\mathrm{Pt} / \mathrm{CeO}_{2}-\mathrm{MW}$ > $\mathrm{Pt} / \mathrm{CeO}_{2}$-Template. This is also the trend for the decrease of the $\mathrm{Ce}^{3+}$ content in the samples (Table 3). As will be discussed below, also the catalytic behaviour follows this sequence.

The assessment of the metallic dispersion by gas chemisorption in supported metal catalysts containing ceria is not easy, as ceria is also able to chemisorb $\mathrm{H}_{2}$ and $\mathrm{CO}$ at room temperature, this producing an overestimation of the metal surface exposed. Nevertheless, an estimation of the amount of Pt surface atoms in these samples can be achieved by determining their catalytic activity in a structure-insensitive reaction. Specifically, toluene hydrogenation in the vapour phase has been used as a test reaction to estimate the amount of Pt atoms exposed in the ceria-supported catalysts $[8,51]$. In this sense, catalytic activity for toluene hydrogenation obtained for all samples after reduction at $350{ }^{\circ} \mathrm{C}$ was compared with the activity of a well-characterized $\mathrm{Pt} / \mathrm{Al}_{2} \mathrm{O}_{3}$ commercial catalyst [52]. In this way, Table 3 shows an estimation of the Pt dispersion in the three $\mathrm{Pt} / \mathrm{CeO}_{2}$ samples. As it can be seen, the values decrease in this order: $\mathrm{Pt} / \mathrm{CeO}_{2}-$ Urea > $\mathrm{Pt} / \mathrm{CeO}_{2}-\mathrm{MW}>\mathrm{Pt} / \mathrm{CeO}_{2}-$ Template, which is the same trend than that showed by the surface Pt/Ce ratios obtained by XPS. These data confirm the higher amount of surface $\mathrm{Pt}$ atoms available in the $\mathrm{Pt} / \mathrm{CeO}_{2}$-Urea catalyst. Summarizing the characterization results, we can see that the different preparation methods lead to different electronic properties of the support as well as different Pt dispersion. It for sure will have a large influence in the catalytic performance. 


\section{Catalytic behaviour}

Fig. 7 shows the WGS catalytic activity of the studied samples under model conditions $\left(\mathrm{CO}+\mathrm{H}_{2} \mathrm{O}\right)$. Pt/ $/ \mathrm{CeO}_{2}-\mathrm{Urea}$ and $\mathrm{Pt} / \mathrm{CeO}_{2}-\mathrm{MW}$ catalysts exhibited similar behaviour, reaching full equilibrium conversions above $300{ }^{\circ} \mathrm{C}$. In contrast, the $\mathrm{Pt} / \mathrm{CeO}_{2}-\mathrm{Template}$ catalyst was out of the trend, resulting hardly active in this reaction.

In order to differentiate the catalytic properties of the $\mathrm{Pt} / \mathrm{CeO}_{2}$-Urea and $\mathrm{Pt} / \mathrm{CeO}_{2}-\mathrm{MW}$ samples, a most demanding WGS inlet was considered. Actually, with the aim to use the WGS reaction as a CO removal step for fuel cells applications, the presence of $\mathrm{CO}_{2}$ and $\mathrm{H}_{2}$ must be considered [53]. Fig. 8 represents the catalytic activity of the studied solids under more realistic feed composition. As expected, the conversion curves shift to higher temperatures when $\mathrm{CO}_{2}$ and $\mathrm{H}_{2}$ are included due to reaction thermodynamics constraints. With these new conditions, the catalytic activity follows this trend: $\mathrm{Pt} / \mathrm{CeO}_{2}-\mathrm{Urea}>\mathrm{Pt} / \mathrm{CeO}_{2}-\mathrm{MW}>\mathrm{Pt} / \mathrm{CeO}_{2}-$ Template. As observed in the model mixture, the $\mathrm{Pt} / \mathrm{CeO}_{2}$-Template sample is the least active within the series. According to the characterization data, this catalyst exhibits the poorest reducibility together with the lowest Pt dispersion. Both properties affect the WGS performance and could explain its insufficient activity. While in the model WGS mixture both $\mathrm{Pt} / \mathrm{CeO}_{2}-\mathrm{Urea}$ and $\mathrm{Pt} / \mathrm{CeO}_{2^{-}}$ MW behaved similarly, the $\mathrm{Pt} / \mathrm{CeO}_{2}$-Urea sample manifested the best catalytic activity under the realistic stream. Several reasons may account for the promoted activity of this sample as deduced from the characterization data.

For the water-gas shift reaction, water dissociation may take place either on the support and the metal particle in the case of $\mathrm{Pt} / \mathrm{CeO}_{2}$ catalysts. Apparently, the key step in the preparation of highly efficient catalysts for the WGS reaction is the presence also of an adequate support with high oxygen mobility able to assists the rate-limiting step water activation $[19,54]$. Our TPR and XPS results reveal that the $\mathrm{Pt} / \mathrm{CeO}_{2}-\mathrm{Urea}$ sample presents the highest reducibility. The enhanced redox properties are associated with electronics perturbations resulting from the strong metal-support contact. As previously reported, this kind of metal particles-support interactions could explain the excellent catalytic activity [33]. In addition to the reducibility, the lowest band gap was observed for the $\mathrm{CeO}_{2}$-Urea support (UV-Vis experiments) indicated a larger concentration of $\mathrm{Ce}^{3+}$ ions and oxygen vacancies in the sample. Such structural defects play an important 
role in the catalytic activity, acting as adsorption points for water activation and assisting the noble metal to complete the catalytic cycle.

In other words, in the WGS redox pathway, it is well known that the formation of carboxyl species takes place in the oxygen vacancies of the support. Consequently, the differences in the activity between the three $\mathrm{Pt} / \mathrm{CeO}_{2}$ catalysts can be explained on the basis of different reaction pathways [55]. In the redox mechanism, $\mathrm{CO}$ adsorbs on $\mathrm{Pt}$ surface sites and it is oxidized by oxygen species from $\mathrm{CeO}_{2}$ which, in turn, is reoxidized by water that adsorbs on the oxide surface generating hydroxyl groups bound to the oxygen vacancies. The main difference between the tested samples could reside on their ability for achieving water dissociation. Thus, while $\mathrm{CO}$ activation only occurs on the Pt particle surface, water dissociation may take place either on the support or on the support and the metal particle surface. The different routes for ceria synthesis results in different concentration of oxygen vacancies in the obtained materials, and hence reduces the band gap and increases the Lewis basicity of the support. Alternatively, if the adsorptive or associative mechanism prevails, the higher concentration of oxygen vacancies is correlated with a high concentration of both active $\mathrm{C}$-containing (C-pool $\mathrm{CO}_{\mathrm{ads}}$, formates, carbonates) and $\mathrm{H}$-containing ( $\mathrm{H}-$ pool $\left.-\mathrm{H}_{2} \mathrm{O}_{\mathrm{ads}}, \mathrm{OH} / \mathrm{H}\right)$ reaction intermediates formed within a "reactive zone" around each Pt particle [56].

However, it must be taken into account that if we assume that the ability of the support for water dissociation was the same for the three $\mathrm{Pt} / \mathrm{CeO}_{2}$ catalysts (despite the differences observed), then the differences in catalytic activity can also be attributed to the $\mathrm{CO}$ adsorption properties on the Pt surface, being the $\mathrm{Pt} / \mathrm{CeO}_{2}$-Urea the sample with the best Pt dispersion. This parameter, together with the $\mathrm{Pt}-\mathrm{CeO}_{2}$ interaction, must be considered for a proper understanding of the WGS results. The TPR profiles evidenced the strongest metal-support interaction for the $\mathrm{Pt} / \mathrm{CeO}_{2}$-Urea sample since the surface reduction of ceria takes place at a lower temperature. On the other hand, the XPS results summarized in Table 3 stand that $\mathrm{Pt} / \mathrm{CeO}_{2}$-Urea catalyst shows the higher $\mathrm{Pt} / \mathrm{Ce}$ ratio, what means that this sample presents the best metallic dispersion, also corroborated by the results obtained by toluene hydrogenation. The partially occupied $f$ states of reduced cerium ions (resulting from the oxygen vacant formation where the Pt has preferential nucleation) acts as an electron donor stabilizing the Pt atoms. All of this properties account for the great activity of the $\mathrm{Pt} / \mathrm{CeO}_{2}$-Urea in the WGS reaction and make it 
suitable for the $\mathrm{CO}$ depletion even when high amounts of $\mathrm{CO}_{2}$ and $\mathrm{H}_{2}$ are included in the reactant mixtures.

Finally, according to our catalytic activity/characterization data, it must be concluded that the conventional method using urea as a precipitant agent is the best option to develop efficient $\mathrm{Pt} / \mathrm{CeO}_{2}$ catalysts for the WGS reaction.

\section{Conclusions}

This study compares three different ceria preparation procedures to develop effective $\mathrm{Pt} / \mathrm{CeO}_{2}$ catalysts for the WGS reaction. Our results clearly demonstrate that the synthesis procedure may modulate the redox and electronic properties of ceria. The type of ceria coming from the studied methods influences the posterior Pt deposition and the final features of the $\mathrm{Pt} / \mathrm{CeO}_{2}$ based catalyst. In particular, the simple and facile conventional urea-assisted homogeneous precipitation method drives to the best redox and electronic skills. Moreover, the best Pt dispersion was obtained for this solid. The Pt catalyst prepared using the urea method was superior to the $\mathrm{Pt} / \mathrm{CeO}_{2}-\mathrm{Template}$ and the $\mathrm{Pt} / \mathrm{CeO}_{2}-\mathrm{MW}$ samples. The enhanced performance of this catalyst becomes especially relevant under realistic WGS conditions.

\section{Acknowledgements}

Financial support from Generalitat Valenciana (project PROMETEOII/2014/004) and MINECO (projects MAT2013-45008-P and MAT2017-86992-R) are gratefully acknowledged. EVRF also thanks MINECO for his Ramon y Cajal fellow RYC-201211427 and the MAT2016-81732-ERC project. LPP also thanks Generalitat Valenciana for her postdoctoral fellow APOSTD2017

\section{References}

[1] Trovarelli A, de Leitenburg C, Boaro M, Dolcetti G. Catal. Today. 1999;50:353.

[2] Montini T, Melchionna M, Monai M, Fornasiero P. Chem. Rev. 2016;116:5987.

[3] Serrano-Ruiz JC, Ramos-Fernández EV, Silvestre-Albero J, Sepúlveda-Escribano A, Rodríguez-Reinoso F. Mater. Res. Bull. 2008;43:1850. 
[4] Silvestre-Albero J, Rodríguez-Reinoso F, Sepúlveda-Escribano A. J. Catal. 2002;210:127.

[5] Yan L, Yu R, Chen J, Xing X. Cryst. Growth Des. 2008;8:1474.

[6] Hu Z, Qiu S, You Y, Guo Y, Guo Y, Wang L, Zhan W, Lu G. Appl. Catal. B: Environ. 2018;225:110.

[7] Rico-Francés S, Jardim EO, Wezendonk TA, Kapteijn F, Gascon J, SepúlvedaEscribano A, Ramos-Fernandez EV. Appl. Catal. B: Environ. 2016;180169.

[8] Vicario M, Llorca J, Boaro M, de Leitenburg C, Trovarelli A. J. Rare Earths. 2009;27:196.

[9] Ramos-Fernandez EV, Shiju NR, Rothenberg G. RSC Adv. 2014;416456.

[10] Trovarelli A. "Front Matter", in: Catalysis by Ceria and Related Materials, Published by Imperial College Press, Distributed by World Scientific Publishing Co., 2002, pp. I-XVII.

[11] Han WQ, Wu LJ, Zhou YM. J. Am. Chem. Soc. 2005;127:12814.

[12] Liu X, Zhou K, Wang L, Wang B, Li Y, J. Am. Chem. Soc. 2009;131:3140.

[13] Wu Z, Li M, Overbury H, J. Catal. 2012;285: 61.

[14] Désaunay T, Bonura G, Chiodo V, Freni S, Couzinié JP, Bourgon J, Ringuedé A, Labat F, Adamo C, Cassir M. J. Catal., 2013;297:193.

[15] Lykaki M, Pachatouridou E, Carabineiro SAC, Iliopoulou E, Andriopoulou C, Kallithrakas-Kontos N, Boghosian S, Konsolakis M. Appl. Catal. B: Environ. 2018;230:18.

[16] Gao Y, Wang W, Chang S, Huang W. ChemCatChem 2013;5:3610.

[17] Tong T, Liu X, Banis MN, Hu Y, Wang Y. J. Catal. 2018;365:420.

[18] Pastor-Pérez L, Reina TR, Ivanova S, Centeno MA, Odriozola JA, SepúlvedaEscribano A. Catalysts 2015;5:298.

[19] Gonzalez-Castaño M, Reina TR, Ivanova S, Centeno MA, Odriozola JA. J. Catal. 2014;314:1.

[20] Jain R, Poyraz AS, Gamliel DP, Valla J, Suib SL, Maric R. Appl. Catal. A: Gen. 2015;507:1. 
[21] Kalamaras CM, Americanou S, Efstahiou AM, J. Catal. 2010;279:287.

[22] Nagai $Y$, Hirabayashi $T$, Dohmae K, Takagi N, Minami T, Shinjoh H, Matsumoto S. J. Catal. 2006;242:103.

[23] Si R, Flytzani-Stephanopoulos M. Angew. Chem. Int. Ed. 2008;47:2884.

[24] Torrente-Murciano L, García-García FR. Catal. Commun. 2015;71:1.

[25] Panagiotopoulou P, Kondaries DI, Catal. Today. 2006;112:49.

[26] Orilall MC, Wiesner U, Chem. Soc. Rev. 2011;40:520.

[27] Thommes M, Kaneko K, Neimark AV, Olivier JP, Rodriguez-Reinoso F, Rouquerol J, Sing KSW. Pure Appl. Chem. 2015;87:1051.

[28] Cao C-Y, Cui Z-M, Chen C-Q, Song W-G, Cai W, J. Phys. Chem. C. 2010;114:9865.

[29] Meher SK, Rao GR, ACS Catal. 2012;2:2795.

[30] Rao KN, Bharali P, Thrimurthulu G, Reddy BM. Catal. Commun. 2010;11:863.

[31] Petrovsky V, Gorman BP, Anderson HU, Petrovsky T, J. Appl. Phys. 2001;90:2517.

[32] Marabelli F, Wachter P. Phys. Rev. B. 1987;36:1238.

[33] Rico-Francés S, Sepúlveda-Escribano A, Ramos-Fernandez EV. Int. J. Hydrogen Energy 2017;42:29262.

[34] Gonzalez Castaño M, Reina TR, Ivanova S, Centeno MA, Odriozola JA. J. Catal. 2014;314:1.

[35] Deshpande S, Patil S, Kuchibhatla SVNT, Seal S. Appl. Phys. Lett. 2005;87:133113.

[36] Tsunekawa S, Fukuda T, Kasuya A. Surf. Sci. 2000;457: L437.

[37] Acerbi N, Golunski S, Tsang SC, Daly H, Hardacre C, Smith R, Collier P. J. Phys. Chem. C. 2012;116:13569.

[38] Ho C, Yu JC, Kwong T, Mak AC, Lai S. Chem. Mater. 2005;17:4514.

[39] Huang XS, Sun H, Wang, LC, Liu YM, Fan KN, Cao Y. Appl. Catal. B 2009;90: 224. 
[40] Jardim EO, Rico-Francés S, Coloma F, Ramos-Fernández EV, Silvestre-Albero J, Sepúlveda-Escribano A. Appl. Catal. A: Gen. 2014;487:119.

[41] Zhibo R, Fei P, Jianwei L, Xin L, Biaohua C, Catalysts 2017;7:48.

[42] Connie MY, YeungKai MK. Yu Qi J, Fu D, Thompsett MI, Petch S, Chi T. J. Am. Chem. Soc.2005;127:51:18010.

[43] Buitrago-Sierra R, Serrano-Ruiz JC, Rodríguez-Reinoso F, Sepúlveda-Escribano A, Dumesic JA. Green Chem. 2012:14:3318.

[44] Abdelouahab-Reddam Z, El Mail R, Coloma F, Sepúlveda-Escribano A. Catal. Today. 2015;249:109.

[45] Sepúlveda-Escribano A, Coloma F, Rodríguez-Reinoso F. J. Catal. 1998;178:649.

[46] Moretti E, Storaro L, Talon A, Riello P, Molina AI, Rodríguez-Castellón E., Appl. Catal. B: Environ. 2015;168-169:385.

[47] Trovarelli A, Dolcetti G, De Leitenburg C, Kašpar J, Finetti P, Santoni A. J. Chem. Soc. Faraday Trans. 1991;88:1311.

[48] Kundu S, Ciston J, Senanayake SD, Arena DA, Fujita E, Stacchiola D, Barrio L, Navarro RM, Fierro JLG, Rodriguez JA. J. Phys. Chem. C. 2012;116:14062.

[49] Senanayake SD, Rodriguez JA, Stacchiola D. Top. Catal. 2013;56:1488.

[50] Ramos-Fernández EV, Ramos-Fernández JM, Martínez-Escandell M, SepúlvedaEscribano A, Rodríguez-Reinoso F. Catal. Letters. 2009;133:267.

[51] Goguet A, Meunier F, Breen JP, Burch R, Petch MI, Faur Ghenciu A. J. Catal. 2004;226:382.

[52] Serrano-Ruiz JC, Luettich J, Sepúlveda-Escribano A, Rodríguez-Reinoso F. J. Catal. 2006;241: 45.

[53] Farrauto RJ, Liu Y, Ruettinger W, Ilinich O, Shore L, Giroux T. Catal. Rev. 2007;49:141.

[54] Reina TR, Ivanova S, Laguna OH, Centeno MA, Odriozola JA. Appl. Catal. B: Environ. 2016;197:67.

[55] Reina TR, Ivanova S, Delgado JJ, Ivanov I, Idakiev V, Tabakova T, Centeno MA, Odriozola JA. ChemCatChem 2014;6:1401. 
[56] Petallidou KC, Kalamaras CM, Efstahiou AM, Catal. Today. 2014;228:183. 
Table 1. Textural properties of supports, and Pt content of catalysts.

\begin{tabular}{lcccc}
\hline \multicolumn{1}{c}{ Sample } & $\mathrm{S}_{\mathrm{BET}}\left(\mathrm{m}^{2} / \mathrm{g}\right)$ & $\mathrm{V}_{\text {micro }}(\mathrm{cc} / \mathrm{g})$ & $\mathrm{V}_{\text {meso }}(\mathrm{cc} / \mathrm{g})$ & $\% \mathrm{Pt}$ \\
\hline $\mathbf{C e O}_{2}$-Urea & 115 & 0.037 & 0.033 & 1.07 \\
$\mathrm{CeO}_{2}$-MW & 134 & 0.043 & 0.048 & 0.99 \\
$\mathbf{C e O}_{2}$-Template & 110 & 0.038 & 0.041 & 0.98 \\
\hline
\end{tabular}


Table 2. Indirect ceria band gap values for the synthesized supports and catalysts calculated by using the Kubelka-Munk method.

\begin{tabular}{lclc}
\hline Sample & Band gap $(\mathbf{e V})$ & Sample & Band gap $(\mathbf{e V})$ \\
\hline $\mathrm{CeO}_{2}$-Urea & 2.66 & $\mathrm{PtCeO}_{2}$-Urea & 1.50 \\
$\mathrm{CeO}_{2}$-MW & 2.72 & $\mathrm{PtCeO}_{2}-\mathrm{MW}$ & 1.63 \\
$\mathrm{CeO}_{2}$-Template & 2.78 & $\mathrm{PtCeO}_{2}$-Template & 1.62 \\
\hline
\end{tabular}


Table 3. Binding energies of the $\mathrm{Pt} 4 \mathrm{f}_{7 / 2}$ level, surface $\mathrm{Pt} / \mathrm{Ce}$ atomic ratios, surface $\mathrm{Ce}^{3+}$ content and Pt dispersion of catalysts reduced at $350{ }^{\circ} \mathrm{C}$.

\begin{tabular}{lcccc}
\hline Reduced samples & $\mathbf{P t} \mathbf{4 f}_{7 / 2}$ & $\mathbf{P t} / \mathbf{C e}$ & $\mathbf{C e}^{3+}(\boldsymbol{\%})$ & $* \mathbf{D}(\boldsymbol{\%})$ \\
\hline $\mathrm{Pt} / \mathrm{CeO}_{2}$-Urea & 72.7 & 0.0145 & 39 & 25 \\
$\mathrm{Pt} / \mathrm{CeO}_{2}$-MW & 71.8 & 0.0110 & 36 & 19 \\
$\mathrm{Pt} / \mathrm{CeO}_{2}$-Template & 71.7 & 0.0105 & 36 & 16 \\
\hline
\end{tabular}

* Pt dispersion determined by toluene hydrogenation. 


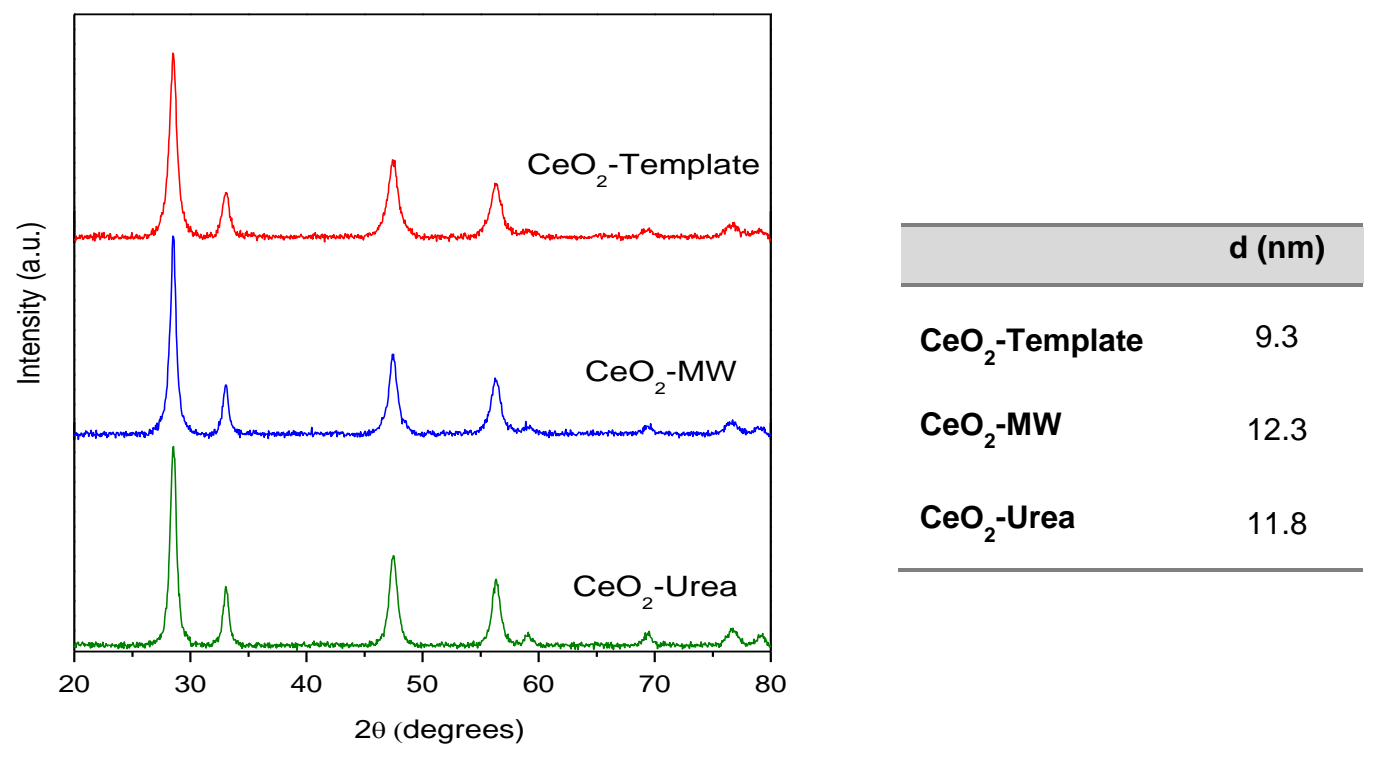

Figure 1. X-ray diffraction patterns and crystal sizes of the $\mathrm{CeO}_{2}$ supports. 


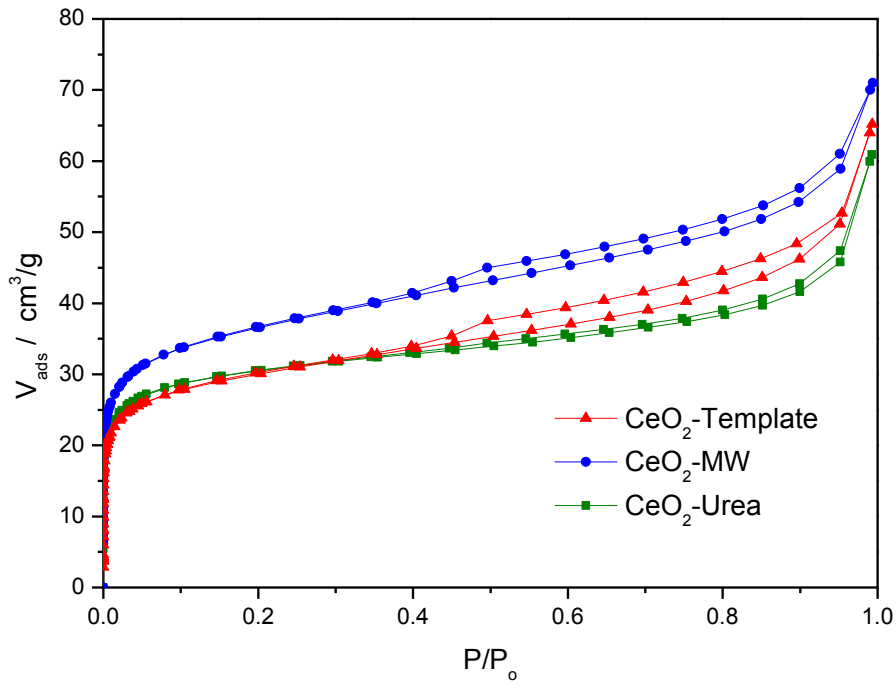

Figure 2. $\mathrm{N}_{2}$ adsorption isotherms at $-196^{\circ} \mathrm{C}$ for the $\mathrm{CeO}_{2}$ supports. 

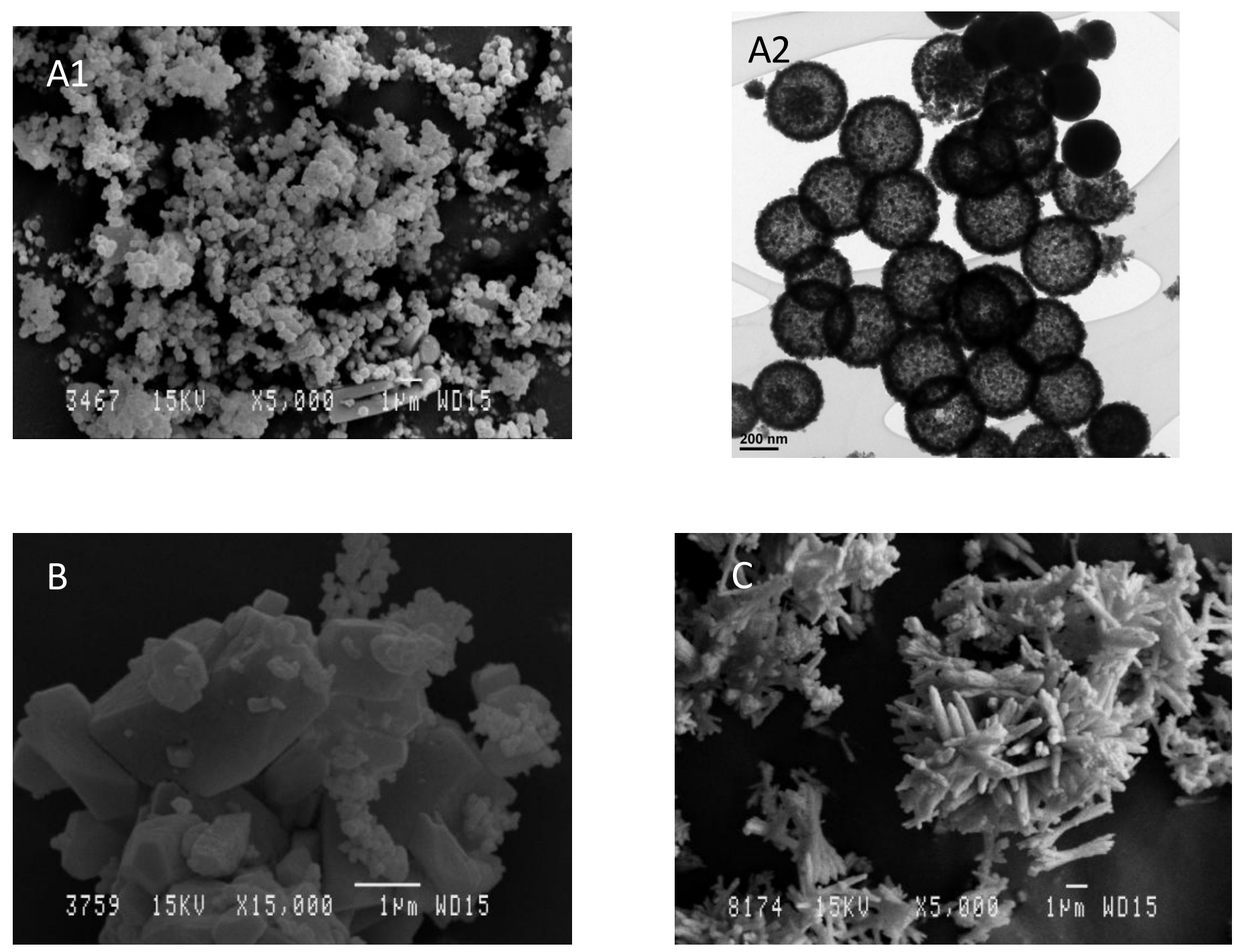

Figure 3. Representative SEM (A1, B, C) and TEM (A2) images of $\mathrm{CeO}_{2}-\mathrm{MW}(\mathrm{A} 1, \mathrm{A2}), \mathrm{CeO}_{2}-\mathrm{Urea}(\mathrm{B})$ and $\mathrm{CeO}_{2}-$ Template (C). 


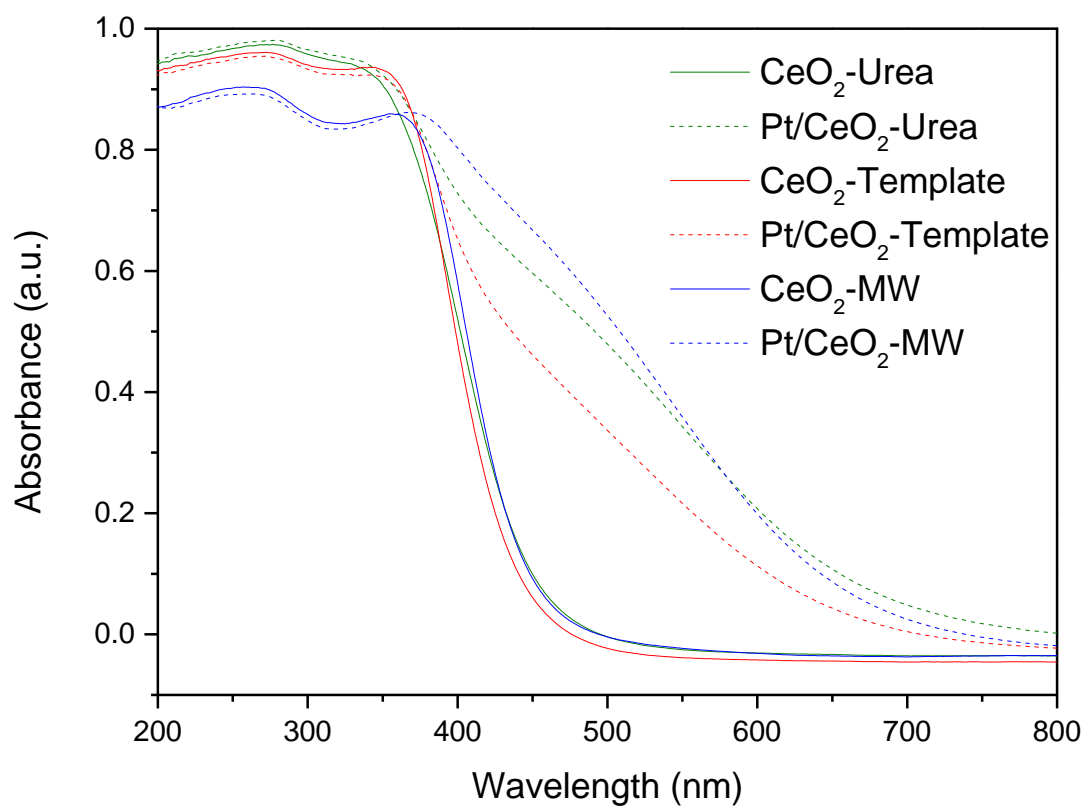

Figure 4. UV-vis spectra of supports and catalysts. 

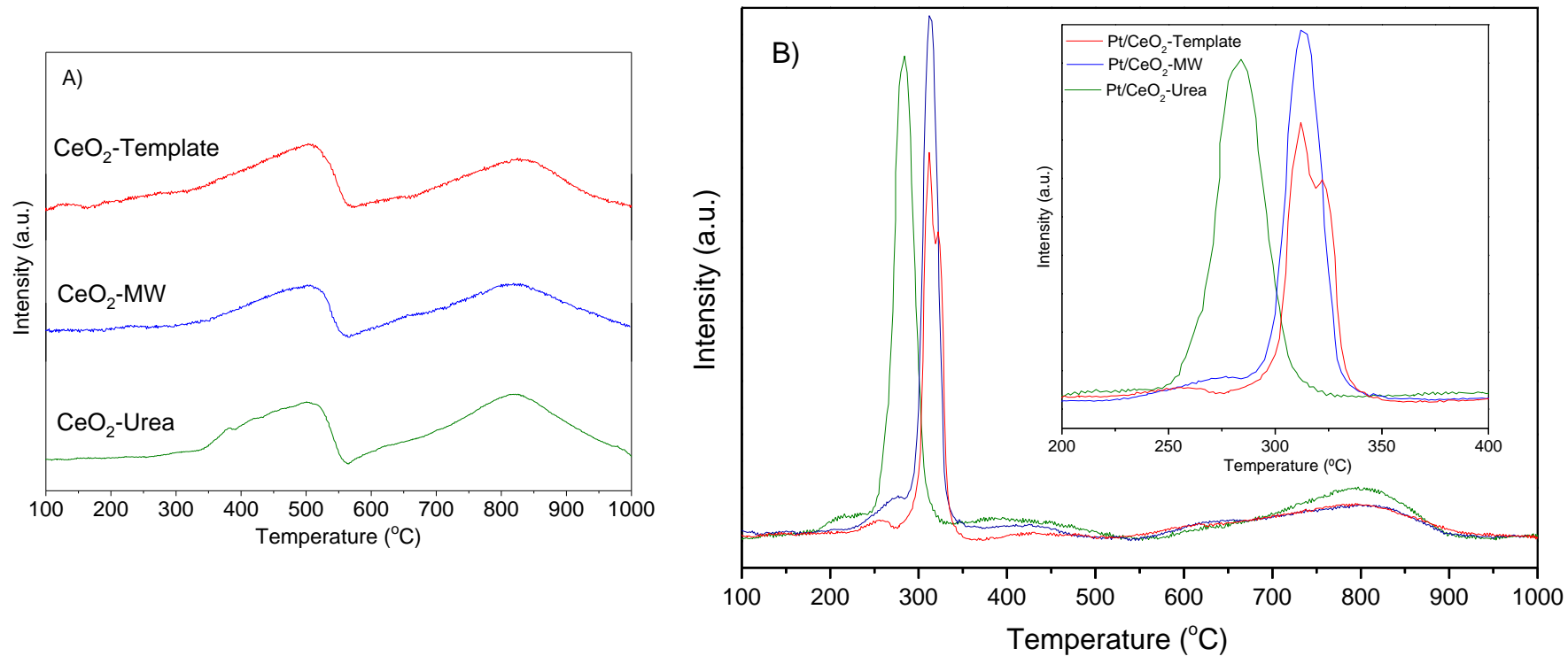

Figure 5. $\mathrm{H}_{2}$-TPR profiles of A) supports and, B) catalysts. 


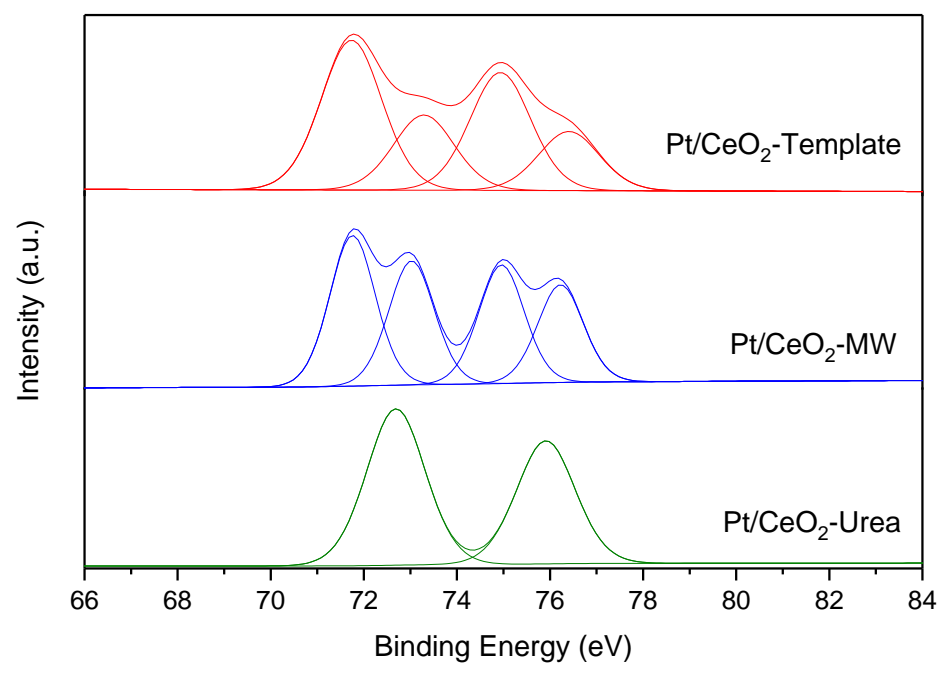

Figure 6. Pt $4 \mathrm{f}$ core level spectra for the reduced catalysts. 


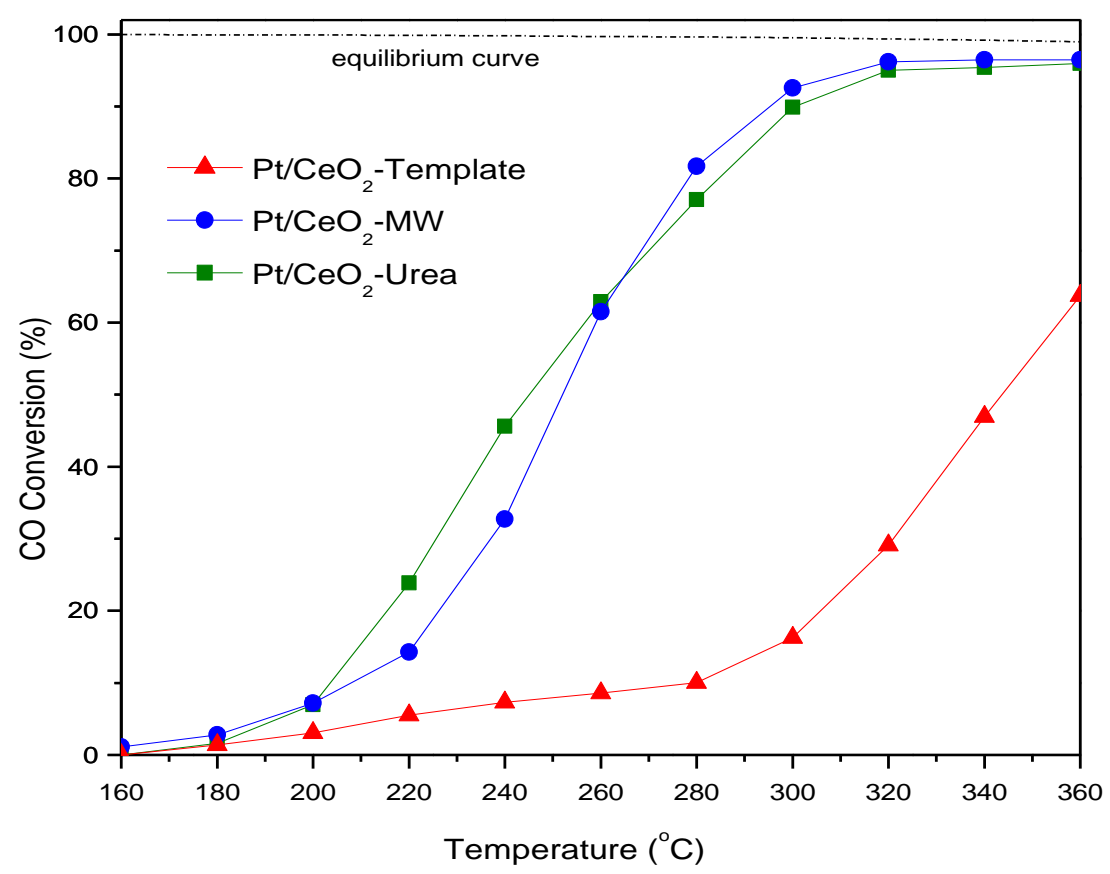

Figure 7. $\mathrm{CO}$ conversion vs. reaction temperature in idealized feed $\left(5 \% \mathrm{CO}, 30 \% \mathrm{H}_{2} \mathrm{O}\right.$, and He balance) for catalysts reduced at $350^{\circ} \mathrm{C}$. 


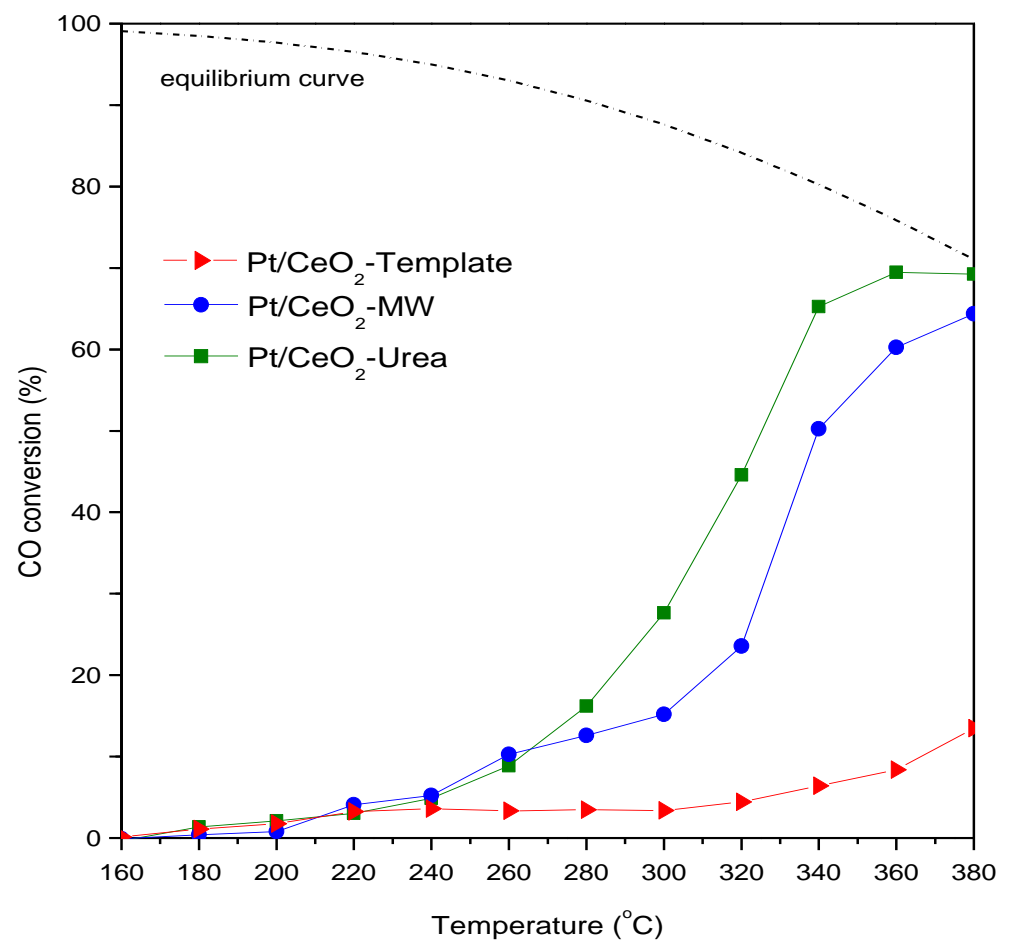

Figure 8. CO conversion vs. reaction temperature in realistic feed $\left(7 \% \mathrm{CO}, 30 \% \mathrm{H}_{2} \mathrm{O}, 50 \% \mathrm{H}_{2}\right.$, and $9 \% \mathrm{CO}_{2}$ in $\mathrm{He}$ balance) for catalysts reduced at $350^{\circ} \mathrm{C}$. 